Article

\title{
Syntheses of 4-Indolylquinoline Derivatives via Reductive Cyclization of Indolylnitrochalcone Derivatives by Fe/HCl
}

\author{
Wen-Chang Chen ${ }^{\dagger}$, Chan-Chieh Lin ${ }^{\dagger}$, Veerababurao Kavala, Chun-Wei Kuo, Chia-Yu Huang and \\ Ching-Fa Yao* \\ Received: 23 November 2015 ; Accepted: 8 December 2015 ; Published: 15 December 2015 \\ Academic Editor: Wim Dehaen \\ Department of Chemistry, National Taiwan Normal University, 88, Sec. 4, Ting-Chow Road, Taipei 116, \\ Taiwan; wcchen@taigenbiotech.com (W.-C.C.); ntnu21236@gmail.com (C.-C.L.); \\ kavalaveeru@gmail.com (V.K.); cwkuo.water@gmail.com (C.-W.K.); tlotras@gmail.com (C.-Y.H.) \\ * Correspondence: cheyaocf@ntnu.edu.tw or cheyaocf@yahoo.com.tw; Tel.: +886-2-29309092 \\ + These authors contributed equally to this work.
}

\begin{abstract}
An easy and efficient procedure for the synthesis of 4-indolylquinoline derivatives is described. This process involves two steps, the first of which is the Michael addition of indole to nitrochalcones promoted by sulfamic acid under solvent free conditions and the second step is a reductive cyclization of the indolylnitrochalcone intermediates to 4 -indolylquinoline derivatives by $\mathrm{Fe} / \mathrm{HCl}$ in ethanol. In both steps, the reactions are clean and the yields of products are high.
\end{abstract}

Keywords: $\mathrm{Fe} / \mathrm{HCl}$; reductive cyclization; 4-indolylquinoline; indolylchalcone

\section{Introduction}

Indole and quinoline are two important class of structural scaffolds that are found in a vast number of natural products and pharmaceutically active compounds [1-6]. Compounds containing both indole and quinoline rings are called as indolylquinolines and are known to exhibit a wide variety of biological activities, including antibiotic, antimicrobial and antifungal activities [7-12]. Although different kinds of indolylquinoline derivatives are known in the literature, three types of indolylquinoline derivatives such as 2-indolylquinoline, 3-indolylquinoline, and 4-indolylquinoline are frequently found in many bioactive compounds. For example, 2-indolylquinoline $[13,14]$ exhibit antistaphylococcal activities, 3-indolylquinolines [15-18] inhibit the activity of PDGF-RTK, 4-indolylquinolines [19-22] have been known for potential treatments for allergic rhinitis, asthma and other inflammatory diseases (Figure 1) [13,14].

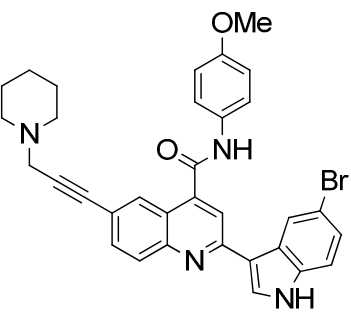

I

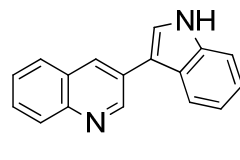

II

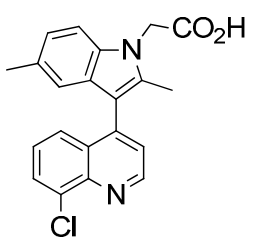

III

Figure 1. Bioactive indolylquinolines derivatives. 
A vast number of protocols are available for the synthesis of 2-indolylquinoline and 3-indolyl-quinoline derivatives [15-18], however, methods which describe the synthesis of 4-indolylquinoline derivatives are limited [19-22]. Marinelli and coworkers described a one-pot synthesis of 4 -indolyl-quinoline derivatives from $\beta$-(2-aminophenyl)- $\alpha, \beta$-ynones [23]. Recently, we reported a method for accessing 4 -indolylquinoline derivatives through an inverse electron-demand aza-Diels-Alder reaction [24]. Some of these reported procedures required functionalized quinoline derivatives such as haloquinolines or indolylboronic acid derivatives and a few methods are associated with the use of expensive metal catalysts and starting materials. Hence, a simple and handy method for the synthesis of 4-indolylquinoline derivatives from easily available starting materials is desirable.

For the past decade, we have been working on the use of reductive cyclization reactions [25-32] to generate a wide variety of nitrogen heterocycles, including indolylquinoline derivatives, 3,3'-biindoles, quinoline derivatives, 2H-1,4-benzoxazin-3-(4H)-ones, carbazolone derivatives, 2,3-disubstituted indole derivatives, acridinones and phenathridine derivatives by using $\mathrm{Fe} / \mathrm{AcOH}$ as a reagent [33-36]. In continuation to our interest on reductive cyclization reactions, we proposed to synthesize 4-indolylquinoline derivatives in two steps starting from 2-nitrochalcone derivatives and indoles. The proposed strategy for the synthesis of 4-indolyl quinoline derivatives is shown in the Scheme 1. This strategy involves two steps: a Michael addition of indole to 2-nitrochalcone followed by the reductive cyclization.

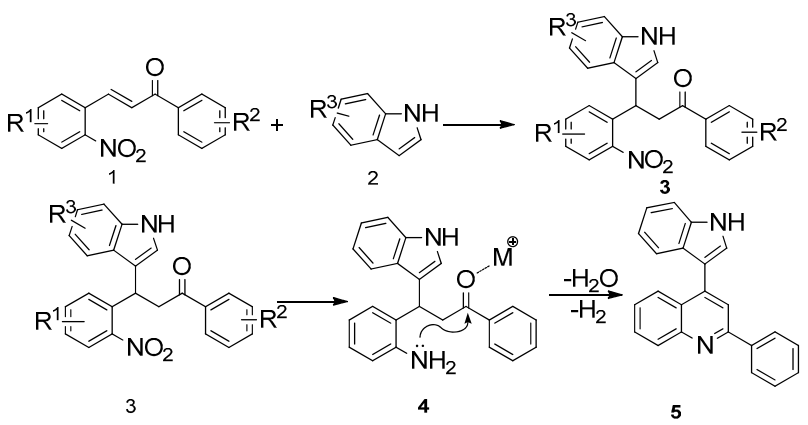

Scheme 1. The proposed strategy for the synthesis of 4-indolyl quinoline derivatives.

\section{Results and Discussion}

To execute our strategy, we need to synthesize the Michael adducts of indoles and various 2-nitrochalcone derivatives. Although, several procedures describe the Michael addition reactions of indoles to chalcones [37-42], to our knowledge there is no procedure available for the Michael addition of 2-nitrochalcone with indole derivatives. On the other hand, we have reported Michael addition reactions of various 2-nitroalkenes and indoles using sulfamic acid as a catalyst under solvent free conditions to obtain the corresponding indolylnitroalkane derivatives in good to excellent yields [30]. We wished to adopt similar conditions to synthesize our starting materials, thus we tested the reaction of indole, 2-nitrochalcone, and sulfamic acid at the temperature of $90{ }^{\circ} \mathrm{C}$ under solvent free conditions. To our delight, the reaction was complete in $4 \mathrm{~h}$ and provided the corresponding 3-(1H-indol-3-yl)-3-(2-nitrophenyl)-1-phenylpropan-1-one derivative was obtained in good yield (Table 1, Entry 1).

Encouraged by this result, we applied these reaction conditions to synthesize various substituted indolylnitrochalcones. The reactions of indole with nitrochalcone derivatives with halogen group (F, $\mathrm{Cl}$ and $\mathrm{Br}$ ) containing 2-nitrobenzalehydes and acetophenone proceeded quickly and afforded the desired products in good to excellent yields (Table 1, Entries 2-4). On the other hand, the reactions of indole with nitrochalcone derivatives derived from 2-nitrobenzaldehyde and ortho halogen group $(\mathrm{Cl}$ or $\mathrm{Br}$ ) substituted acetophenones took place smoothly to provide the corresponding Michael adducts in quantitative yields. 
Table 1. Michael addition of various 2-nitrochalcones and indole.

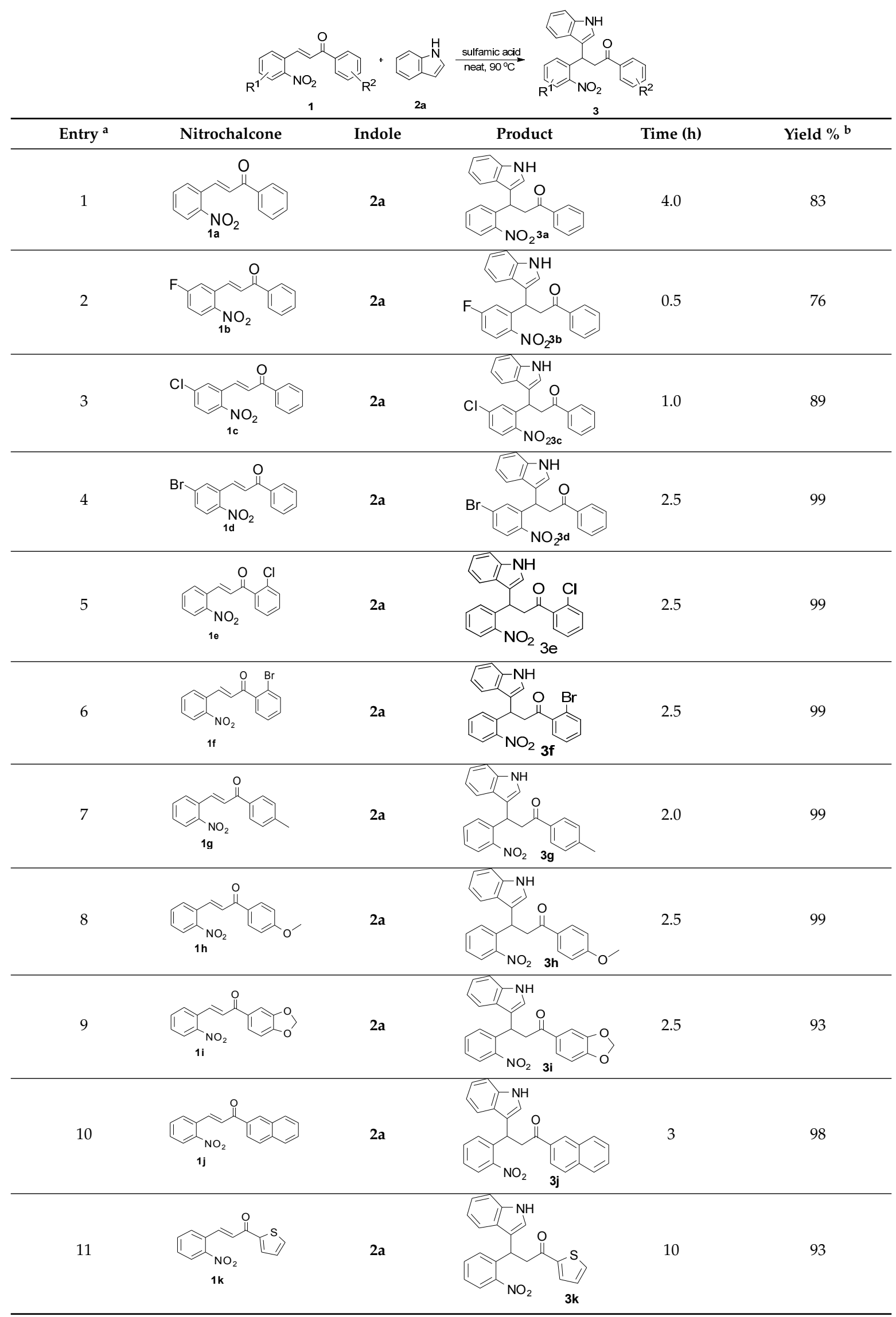

${ }^{a}$ All reactions were carried out by using 1.0 equiv. of $\mathbf{1}$ and 1.2 equiv. of $\mathbf{2 a}$ in the presence of $50 \mathrm{~mol} \%$ of sulfamic acid; ${ }^{b}$ Isolated yields. 
Next, we investigated the reactions of unsubstituted nitrochalcone and various substituted indoles (Table 2).

Table 2. Michael addition of 2-nitrochalcone (1a) and various indoles.

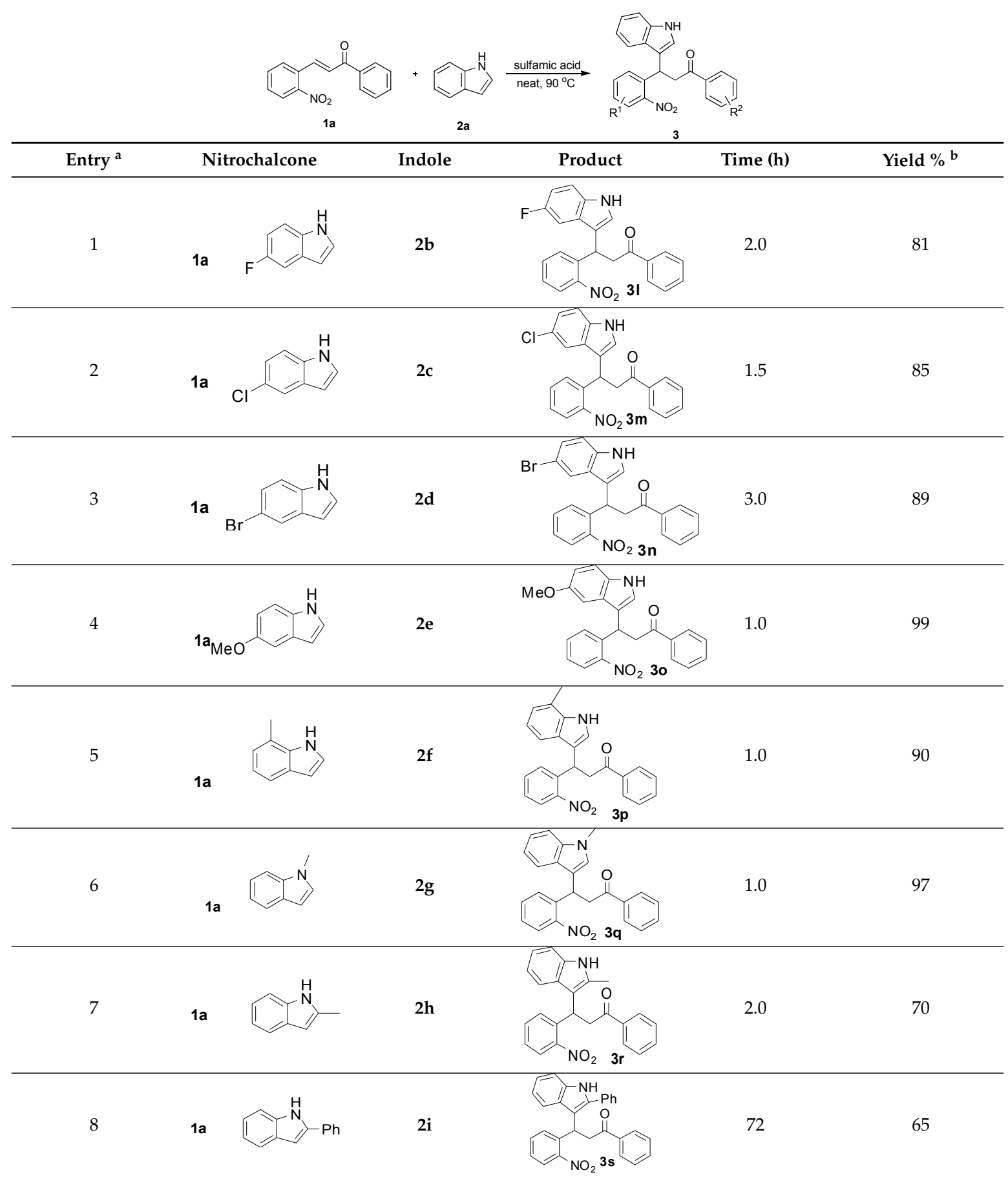

${ }^{a}$ All reactions were carried out by using 1.0 equiv. of $\mathbf{1}$ and 1.2 equiv. of $\mathbf{2 a}$ in the presence of $50 \mathrm{~mol} \%$ of sulfamic acid; ${ }^{\mathrm{b}}$ Isolated yields.

When nitrochalcone was treated with electron-withdrawing group containing indoles such as 5-fluoroindole, 5-chloroindole and 5-bromoindole, the reactions produced the corresponding Michael adducts in good yields. On the other hand, the reactions of nitrochalcone and electron-donating indoles such as 5-methoxyindole and 6-methylindole provided its corresponding Michael adducts in excellent yields. Next, the reaction of $N$-methylindole and 2-nitrochalcone afford the desired Michael adduct in excellent yield. Further, the reaction of 2-nitrochalcone with 2-phenylindole 
or 2-methylindole afforded the corresponding Michael adducts in moderate yields. Moreover, the reactions of 2-nitrochalcone with 2-phenylindole or 2-methylindole took longer to go to completion (Table 2).

After the preparation of various substituted 3-(1H-indol-3-yl)-3-(2-nitrophenyl)-1-phenylpropan-1-one derivatives, we then focused on the reductive cyclization of these compounds to 4-indolylquinoline derivatives. Initially, we treated 3-(1H-indol-3-yl)-3-(2-nitrophenyl)-1-phenylpropan-1-one with the standard reductive cyclization agent Fe/AcOH [9] (Table 3, entry 1). Under these conditions the reaction afforded two compounds. From the ${ }^{1} \mathrm{H}$ - and ${ }^{13} \mathrm{C}-\mathrm{NMR}$ spectral data and mass spectral analysis, it was revealed that the major product was the 4-indolylquinoline derivative and the minor product was the indole-eliminated 2-phenylquinoline derivative.

Then, we tried $\mathrm{Zn}$ as reducing reagent (Table 3, entries 2 and 3), but the results were not encouraging. As it is reported in the literature $[43,44]$ that $\mathrm{Fe} / \mathrm{HCl}$ is an efficient reductive cyclizing agent, next, we used $\mathrm{Fe} / \mathrm{HCl}$ in $\mathrm{EtOH}$ (Table 3, entry 4) for this transformation. To our delight, the reaction produced the indolylquinoline derivative in excellent yield without any of the minor product. Further, when the reaction was performed using a mixed solvent such as ethanol and water (1:1), the reaction afforded an excellent yield of the 4-indolylquinoline derivative (Table 3, entry 5). However, the reaction time was longer in this case. Furthermore, when the reaction was performed in methanol it resulted in a decreased yield of the desired product (Table 3, entry 6). From the optimization results, the reaction condition using $\mathrm{Fe} / \mathrm{HCl}$ in ethanol at reflux temperature (Table 3, entry 5) were found to be the best condition for the synthesis of 4-indolylquinoline derivatives from the corresponding 3-(1H-indol-3-yl)-3-(2-nitrophenyl)-1-phenylpropan-1-one derivatives (Table 3).

Table 3. Optimization studies for reductive cyclization of 3-(1H-indol-3-yl)-3-(2-nitrophenyl)-1phenylpropan-1-one (3a)

\begin{tabular}{|c|c|c|c|c|c|}
\hline Entry $^{a}$ & Reductant & Solvent & Time (h) & Yield of $4 a(\%)^{b}$ & Yield of $5 a(\%){ }^{b}$ \\
\hline 1 & $\mathrm{Fe}$ & $\mathrm{AcOH}$ & 0.5 & 72 & 24 \\
\hline 2 & $\mathrm{Zn}$ & $\mathrm{AcOH}$ & 10 & 16 & 21 \\
\hline 3 & $\mathrm{Zn}^{\mathrm{c}}$ & $\mathrm{THF}-\mathrm{H}_{2} \mathrm{O}^{\mathrm{d}}$ & 2.0 & 0 & 0 \\
\hline 4 & $\mathrm{Fe}^{\mathrm{e}}$ & EtOH & 1.0 & 90 & 0 \\
\hline 5 & $\mathrm{Fe}^{\mathrm{e}}$ & $\mathrm{EtOH}-\mathrm{H}_{2} \mathrm{O}^{\mathrm{f}}$ & 4.0 & 88 & 0 \\
\hline 6 & $\mathrm{Fe}^{\mathrm{e}}$ & $\mathrm{MeOH}$ & 10 & 57 & 0 \\
\hline
\end{tabular}

${ }^{a}$ 3a (1.0 equiv.), metal (6.0 equiv.), solvent $(10 \mathrm{~mL}) ;{ }^{\mathrm{b}}$ Isolated yields; ${ }^{\mathrm{c}} \mathrm{NH}_{4} \mathrm{Cl}$ (1.1 equiv.); ${ }^{\mathrm{d}} \mathrm{THF}-\mathrm{H}_{2} \mathrm{O}$ (2:1);

e $\mathrm{HCl}\left(1.0\right.$ equiv.); ${ }^{\mathrm{f}} \mathrm{EtOH}-\mathrm{H}_{2} \mathrm{O}(4: 1)$.

Having the optimized reaction conditions in hand, we then investigated the scope and limitations of this protocol. As shown in Table 4, 3-(1H-indol-3-yl)-3-(2-nitrophenyl)-1-phenylpropan1-one (3a) reacted under optimized reaction conditions to produce the 4-indolyl-quinoline derivatives in excellent yield.

Under the present reaction conditions, the substrates containing electron-withdrawing groups ( $\mathrm{F}, \mathrm{Cl}$ and $\mathrm{Br}$ ) in the nitrochalcone part of 3-(1H-indol-3-yl)-3-(2-nitrophenyl)-1-phenylpropan-1-one reacted well and afforded the corresponding 4-indolyl-quinoline derivatives in good yields, while the reactions of the substrates possessing electron-donating groups provided the desired 4-indolylquinoline derivatives in excellent yields. Moreover, the substrate bearing a naphthalene ring also provided the corresponding product in $93 \%$ yield under the present reaction conditions. Next, the 3-(1H-indol-3-yl)-3-(2-nitrophenyl)-1-phenylpropan-1-one derivative containing a thiophene group was also reacted under the present reaction conditions to obtain the corresponding indolylquinoline derivative in excellent yield (Table 4). 
Table 4. Reductive cyclization of substituted 3-(1H-indol-3-yl)-3-(2-nitrophenyl)-1-phenylpropan-1-one derivatives derived from various 2-nitrochalcone and indoles.

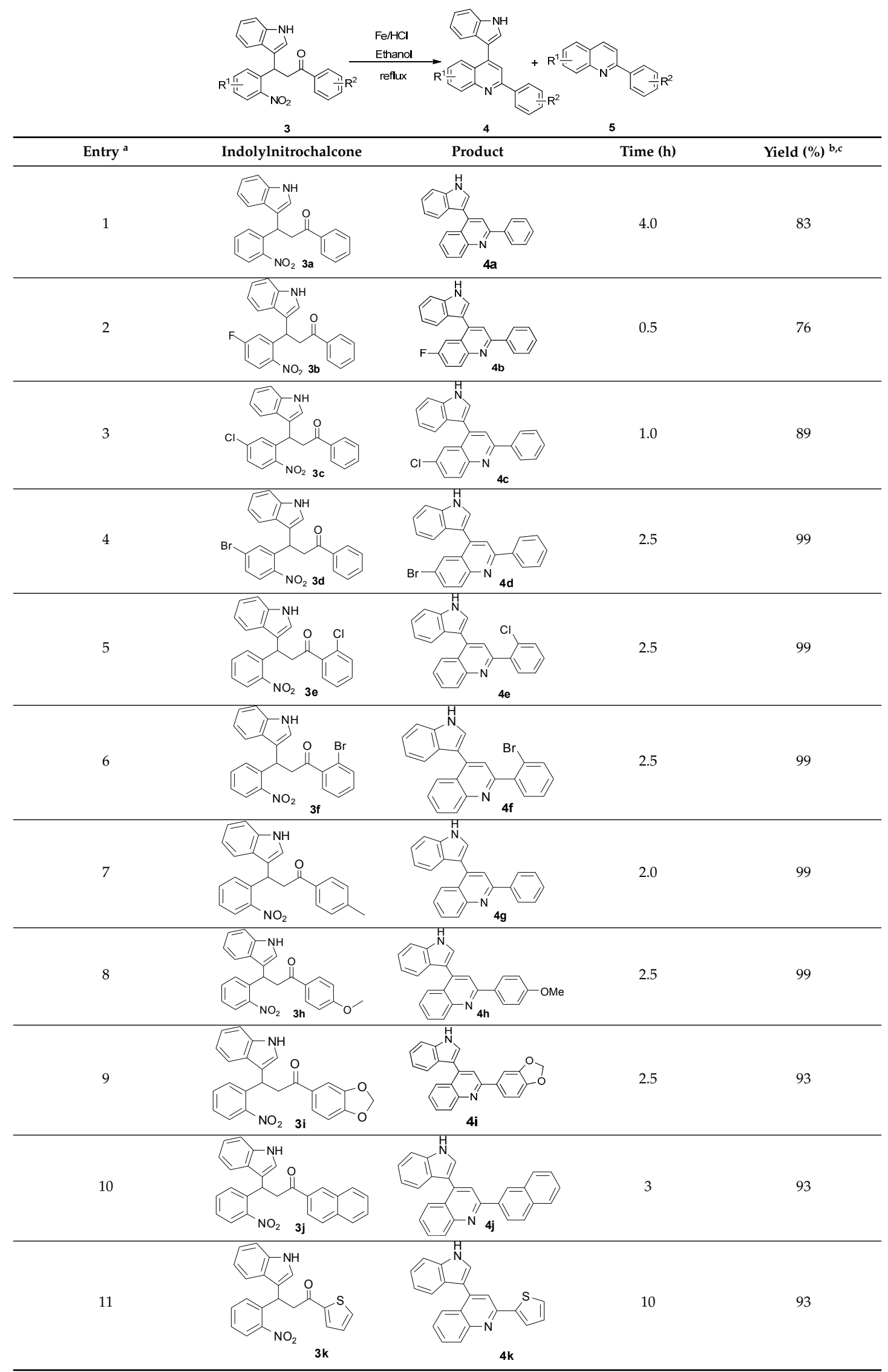

${ }^{a}$ Condition: 3 (1.0 equiv.), Fe (6.0 equiv.), $\mathrm{HCl}$ (1.0 equiv.), EtOH $(10 \mathrm{~mL}){ }^{\mathrm{b}}$ Isolated yields; ${ }^{\mathrm{c}}$ no trace of $\mathbf{5}$ was observed. 
Next, we investigated the reactions of Michael adducts derived from nitrochalcone and various indoles. As shown in the Table 5, the 3-(1H-indol-3-yl)-3-(2-nitrophenyl)-1-phenylpropan-1-one derivatives derived from electron poor indoles (fluoro-, chloro-, and bromoindoles) underwent a smooth reductive cyclization to afford the desired 4-indolylquinoline derivatives in excellent yield, whereas, the substrates derived from the electron rich indoles produced the corresponding indolylquinoline derivatives in slightly lower yields than those of electron poor indoles. It is notable that the reactions of the substrate obtained from 2-phenyl or 2-methylindole provided the corresponding 4-indolylquinoline derivative in moderate yield along with a substantial amount of the indole cleaved product as byproduct. These results show that steric hindrance influences the elimination of indole to produce the indole-cleaved product (Table 5).

To further examine the influence of steric hindrance, we investigated the reactions of the 3-(1H-indol-3-yl)-3-(2-nitrophenyl)-1-phenylpropan-1-one substrates containing a methyl group adjacent to the nitro group as well the substrates derived from 2,5-dimethylindoles. As shown in the Table 6, steric hindrance adjacent to the nitro group has less influence on the reaction outcome, as the substrate $3 \mathbf{t}$ gave the corresponding indolylquinoline in good yield along with traces of the indole cleaved product. However, when the substrate $3 \mathbf{u}$ derived from 2,5-dimethylindole was treated under the present reaction conditions, we obtained $66 \%$ of indolylquinoline derivative and $30 \%$ of indole-cleaved product. Furthermore, we obtained only indole-cleaved product, when the substrate $3 \mathbf{v}$ containing a methyl group adjacent to the nitro as well as the second indole position was used. It is important to note that the reactions took longer when the methyl group was adjacent to the nitro group as in case of entries 2, 3 in Table 6.

Table 5. Reductive cyclization of 3-(1H-indol-3-yl)-3-(2-nitrophenyl)-1-phenylpropan-1-one derivatives derived from various indoles and 2-nitrochalcone.

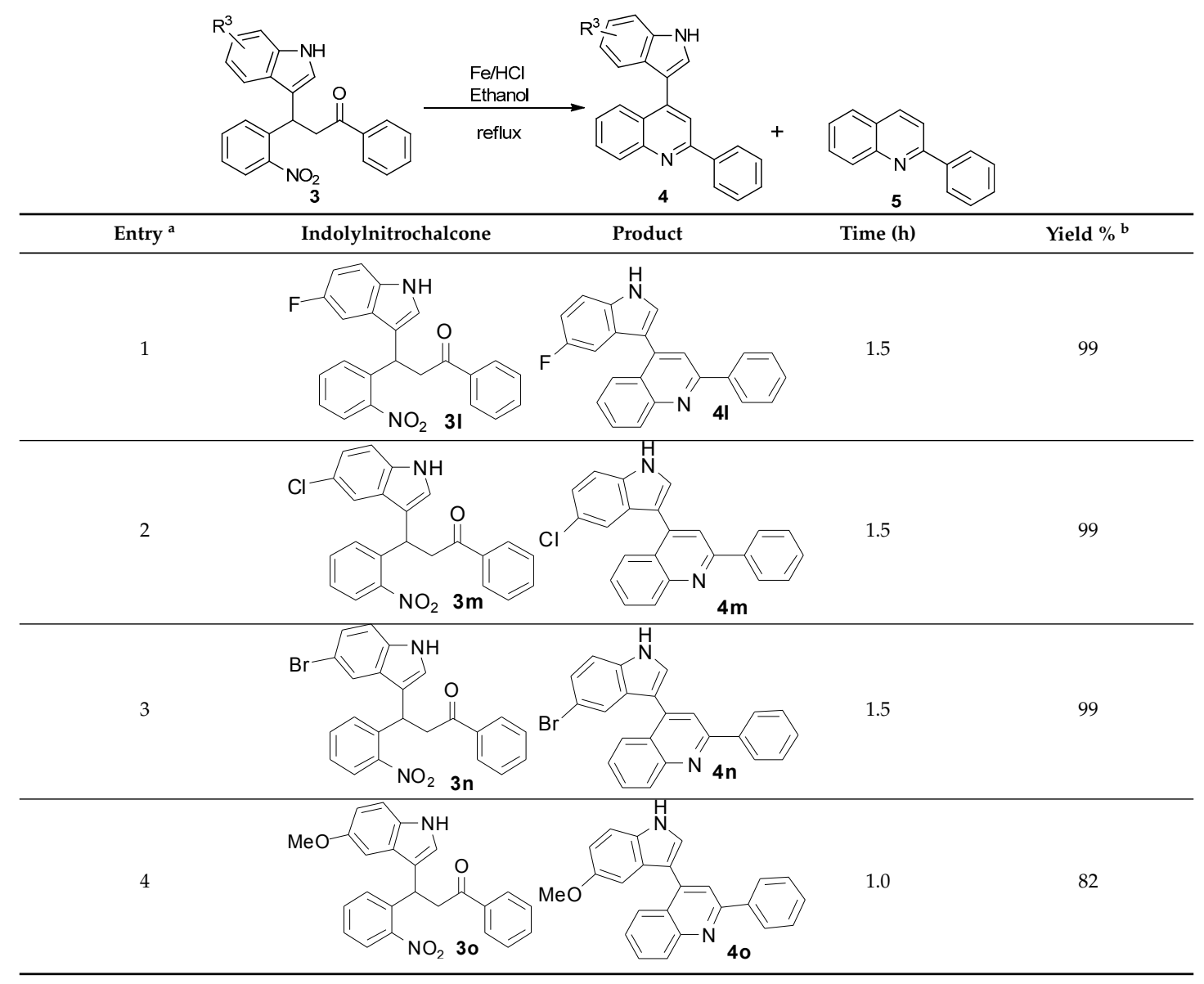


Table 5. Cont.

Entry $^{\mathrm{a}}$

${ }^{\text {a }}$ Condition: 3 (1.0 equiv.), $\mathrm{Fe}$ (6.0 equiv.), $\mathrm{HCl}$ (1.0 equiv.), $\mathrm{EtOH}(10 \mathrm{~mL}) ;{ }^{\mathrm{b}}$ Isolated yields; ${ }^{\mathrm{c}} 17 \%$ of product 5 formed along with $4 \mathrm{r}(66 \%) ;$ d $30 \%$ of 5 formed along with $4 \mathrm{~s}(57 \%)$

Table 6. Reductive cyclization of sterically hindered 3-(1H-indol-3-yl)-3-(2-nitrophenyl)-1-phenylpropan1-one derivatives.

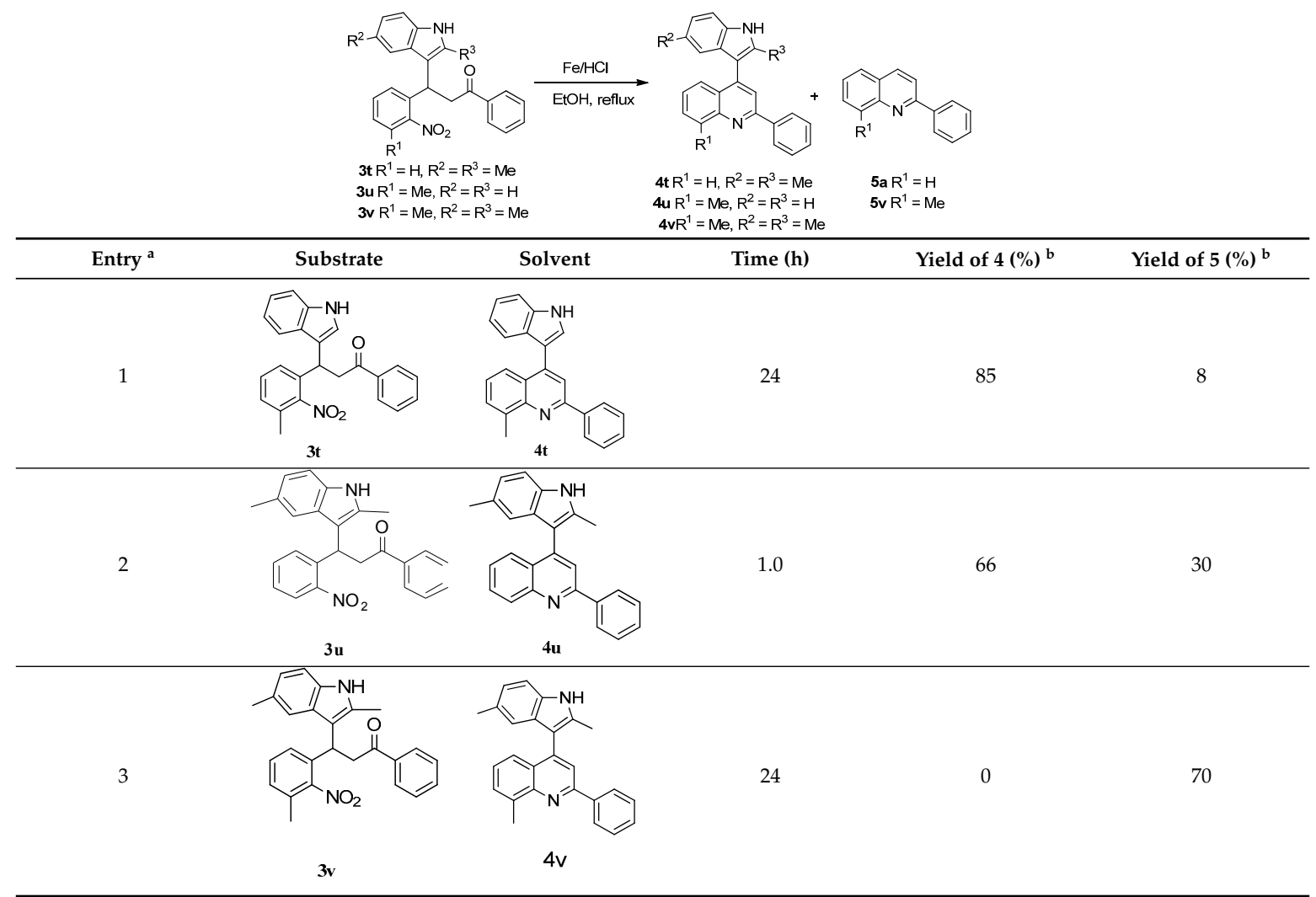

${ }^{\mathrm{a}}$ Condition: 3 (1.0 equiv.), $\mathrm{Fe}$ (6.0 equiv.), $\mathrm{HCl}$ (1.0 equiv.), $\mathrm{EtOH}(10 \mathrm{~mL}) ;{ }^{\mathrm{b}}$ Isolated yields. 
A reaction mechanism for the formation of the indolylquinoline as well as the indole-cleaved product from 3-(1H-indol-3-yl)-3-(2-nitrophenyl)-1-phenylpropan-1-one (3a) is proposed based on our previous work (Scheme 2). Initially, the nitro group of the 3-(1H-indol-3-yl)-3-(2nitrophenyl)-1-phenylpropan-1-one (3a) is reduced to an amino group by $\mathrm{Fe} / \mathrm{HCl}$, then it attacks the carbonyl group in the presence of $\mathrm{FeCl}_{3}$ in the solvent, forming a dihydroquinoline intermediate. The dihydroquinoline intermediate compound is unstable, and undergoes aromatization by the loss of hydrogen or the indole moiety to give either $4 \mathbf{a}$ or $5 \mathbf{a}$. Besides, we also anticipate that indolylquinoline derivative 4a may also undergo a slow decomposition to indole-cleaved product 5a through reductive elimination. To explore this reductive elimination possibility, the indolylquinoline 4 a was treated with $\mathrm{Fe} / \mathrm{AcOH}$ under the identical conditions used in the preparation of indolylquinoline derivatives. We obtained around $14 \%$ of indole-cleaved product along with $82 \%$ of the unchanged indolylquinoline $4 \mathbf{a}$ after $24 \mathrm{~h}$. The result was similar even when reaction was conducted with $\mathrm{Fe} / \mathrm{HCl}$ used as reagent in ethanol. However, when the reaction was performed with $\mathrm{FeCl}_{3}$, the indolylquinoline was unchanged. From these experiments, we cannot exclude this route for the formation of the indole-cleaved product.

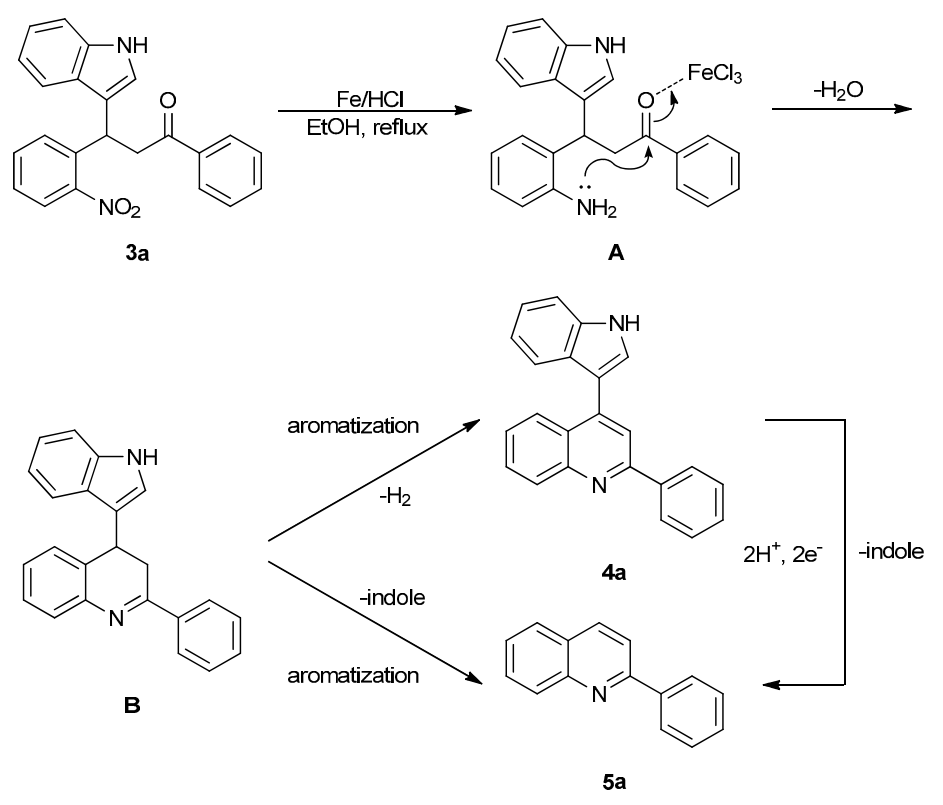

Scheme 2. Mechanistic route for the reductive cyclization of 3-(1H-indol-3-yl)-3-(2-nitrophenyl)1-phenylpropan-1-one derivatives.

\section{Experimental Section}

\subsection{General Information}

All chemicals were purchased from various commercial sources and used directly without further purification. Analytical thin-layer chromatography was performed using E. Merck (New York, NY, USA) silica gel 60F glass plates and E. Merck silica gel 60 (230-400 mesh) was used in flash chromatography separations. MS were measured by a JMS-HX110 spectrometer (JEOL, Hsinchu, Japan). HRMS spectra were recorded using ESI-TOF or EI+ mode or FAB+. ${ }^{1} \mathrm{H}-(400 \mathrm{MHz})$ and ${ }^{13} \mathrm{C}-\mathrm{NMR}(100 \mathrm{MHz})$ spectra were recorded with an Advance EX $400 \mathrm{MHz}$ spectrometer (Bruker, San Francisco, CA, USA). Chemical shifts are reported in parts per million $(\delta)$ using TMS as an internal standard and coupling constant were expressed in hertz. IR spectra were performed on a 100 series FT-IR instrument (Perkin Elmer, Waltham, MA, USA). Melting points were recorded using a capillary melting point apparatus (Electrothermal, Staffordshire, UK) and are uncorrected. All substrates were prepared using literature procedures. 


\subsection{General Procedure for the Reaction of Indoles with Nitrochalcones to give Products $\mathbf{3 a}-\mathbf{3 v}$}

The mixture of nitrochalcone $(2.0 \mathrm{mmol})$, indole $(2.2 \mathrm{mmol})$, and sulfamic acid (1 mmol, 0.5 eq.) was heated at $90{ }^{\circ} \mathrm{C}$ until the complete consumption of starting materials, which was monitored by TLC. Then, the reaction mixture was allowed to cool to room temperature, diluted with ethyl acetate $(20 \mathrm{~mL})$ and washed with water, followed by brine. The organic layer was separated, dried over anhydrous $\mathrm{MgSO}_{4}$, and concentrated in vacuum to obtain the crude product. The residue was purified by flash column chromatography (petroleum ether/ethyl acetate) to obtain the desired products $\mathbf{3 a}-\mathbf{3 v}$. (The ${ }^{1} \mathrm{H}-,{ }^{13} \mathrm{C}-\mathrm{NMR}$ spectra of the compounds (3a-3v) was showed in Supplementary).

3-(1H-Indol-3-yl)-3-(2-nitrophenyl)-1-phenylpropan-1-one (3a): Pale crystalline yellow solid (crystallized from ethyl acetate and hexane) with a melting point of $176-178{ }^{\circ} \mathrm{C}$; IR (KBr): 3320, 3050, 1684, 1525, 1354, $741 \mathrm{~cm}^{-1} .{ }^{1} \mathrm{H}-\mathrm{NMR}\left(\mathrm{DMSO}_{6}\right) \delta 10.99(\mathrm{~s}, 1 \mathrm{H}), 8.00(\mathrm{~d}, J=7.5 \mathrm{~Hz}, 2 \mathrm{H}), 7.83(\mathrm{~d}, J=8.0 \mathrm{~Hz}, 1 \mathrm{H})$, $7.61(\mathrm{~d}, J=6.3 \mathrm{~Hz}, 2 \mathrm{H}), 7.54-7.48(\mathrm{~m}, 3 \mathrm{H}), 7.42-7.36(\mathrm{~m}, 2 \mathrm{H}), 7.38-7.33(\mathrm{~m}, 2 \mathrm{H}), 7.04(\mathrm{t}, J=7.3 \mathrm{~Hz}$, $1 \mathrm{H}), 6.90(\mathrm{t}, J=4.7 \mathrm{~Hz}, 1 \mathrm{H}), 5.45(\mathrm{t}, J=6.8 \mathrm{~Hz}, 1 \mathrm{H}), 4.04(\mathrm{dd}, J=18.0,6.4 \mathrm{~Hz}, 1 \mathrm{H}), 3.88(\mathrm{dd}, J=18.0$, 7.6 Hz, 1H); ${ }^{13}$ C-NMR (DMSO-d 6 ) $\delta 197.8,149.7,138.0,136.4,136.4,133.3,132.6,130.1,128.6,128.0$, $127.2,126.2,123.7,123.1,121.2,118.6,118.4,116.2,111.5,44.5,31.5$; MS (EI) $m / z$ (relative intensity) 370 $\left(\mathrm{M}^{+}\right.$, 36), 353 (47), 251 (100), 231 (59), 204 (65), 105 (87); HRMS (EI) $m / z$ calcd for $\mathrm{C}_{23} \mathrm{H}_{18} \mathrm{~N}_{2} \mathrm{O}_{3}\left(\mathrm{M}^{+}\right)$ 370.1317 , found 370.1310 .

3-(5-Fluoro-2-nitrophenyl)-3-(1H-indol-3-yl)-1-phenylpropan-1-one (3b): Purified by column chromatography using 1:5 ethyl acetate and hexane. After concentration in vacuo it give a brown oil; IR (KBr): 3340, 3056, 1670, 1601, 1520, 1474, 1347, 1287, 974, $623 \mathrm{~cm}^{-1} .{ }^{1} \mathrm{H}-\mathrm{NMR}\left(\mathrm{CDCl}_{3}\right) \delta 8.16(\mathrm{~s}, 1 \mathrm{H}), 7.97-7.95$ $(\mathrm{m}, 2 \mathrm{H}), 7.90(\mathrm{dd}, J=9.0,5.2 \mathrm{~Hz}, 1 \mathrm{H}), 7.56(\mathrm{t}, J=7.4 \mathrm{~Hz}, 1 \mathrm{H}), 7.47-7.43(\mathrm{~m}, 3 \mathrm{H}), 7.32(\mathrm{~d}, J=8.2 \mathrm{~Hz}$, $1 \mathrm{H}), 7.16(\mathrm{dt}, J=7.6,0.7 \mathrm{~Hz}, 1 \mathrm{H}), 7.12-7.09(\mathrm{~m}, 2 \mathrm{H}), 7.03(\mathrm{dt}, J=7.1,0.4 \mathrm{~Hz}, 1 \mathrm{H}), 6.95(\mathrm{ddd}, J=9.2$, 6.5, $2.7 \mathrm{~Hz}, 1 \mathrm{H}), 5.79(\mathrm{t}, J=7.1 \mathrm{~Hz}, 1 \mathrm{H}), 3.86(\mathrm{dd}, J=17.3,7.4 \mathrm{~Hz}, 1 \mathrm{H}), 3.76(\mathrm{dd}, J=17.3,7.4 \mathrm{~Hz}$, $1 \mathrm{H}) ;{ }^{13} \mathrm{C}-\mathrm{NMR}\left(\mathrm{CDCl}_{3}\right) \delta 197.4,164.7\left(\mathrm{~d}, J_{C-F}=254 \mathrm{~Hz}\right), 146.1\left(\mathrm{~d}, J_{C-F}=3 \mathrm{~Hz}\right), 143.2,143.1,136.7$ $\left(\mathrm{d}, J_{C-F}=10 \mathrm{~Hz}\right), 133.6,128.9,128.3,127.5\left(\mathrm{~d}, J_{C-F}=10 \mathrm{~Hz}\right), 126.5,122.8,122.2,120.1,119.4,117.0(\mathrm{~d}$, $\left.J_{C-F}=24 \mathrm{~Hz}\right), 116.9,114.6\left(\mathrm{~d}, J_{C-F}=23 \mathrm{~Hz}\right), 111.5,44.9,33.2 ; \mathrm{HRMS}(\mathrm{EI}) \mathrm{m} / z$ calcd for $\mathrm{C}_{23} \mathrm{H}_{18} \mathrm{~N}_{2} \mathrm{O}_{3} \mathrm{~F}$ $\left([\mathrm{M}+\mathrm{H}]^{+}\right)$389.1301, found 389.1318.

3-(5-Chloro-2-nitrophenyl)-3-(1H-indol-3-yl)-1-phenylpropan-1-one (3c): Purified by column chromatography using 1:4 ethyl acetate and hexane. After concentration in vacuo a pale brown solid with a melting point of $151-153{ }^{\circ} \mathrm{C}$ was obtained; ${ }^{1} \mathrm{H}-\mathrm{NMR}\left(\mathrm{CDCl}_{3}\right) \delta 8.09(\mathrm{~s}, 1 \mathrm{H}), 7.95(\mathrm{~d}, J=8.0 \mathrm{~Hz}, 2 \mathrm{H}), 7.78(\mathrm{~d}$, $J=8.7,1 \mathrm{H}), 7.55(\mathrm{t}, J=7.4 \mathrm{~Hz}, 1 \mathrm{H}), 7.46-7.42(\mathrm{~m}, 3 \mathrm{H}), 7.38(\mathrm{~d}, J=2.0,1 \mathrm{H}), 7.33(\mathrm{~d}, J=8.1,1 \mathrm{H}), 7.25(\mathrm{~s}$, $1 \mathrm{H}), 7.16(\mathrm{t}, J=7.4,1 \mathrm{H}), 7.12(\mathrm{~s}, 1 \mathrm{H}), 7.03(\mathrm{t}, J=7.6,1 \mathrm{H}), 5.73(\mathrm{t}, J=7.2,1 \mathrm{H}), 3.87(\mathrm{dd}, J=17.4,6.8 \mathrm{~Hz}$, $1 \mathrm{H}), 3.75(\mathrm{dd}, J=17.2,7.7 \mathrm{~Hz}, 1 \mathrm{H}) ;{ }^{13} \mathrm{C}-\mathrm{NMR}\left(\mathrm{CDCl}_{3}\right) \delta 197.3,148.4,141.4,139.1,136.8,136.7,133.6$, $130.2,128.9,128.3,127.6,126.5,126.1,122.8,122.2,120.1,119.4,116.8,111.5,44.9,32.9 ; \mathrm{MS}$ (EI) $\mathrm{m} / z$ (relative intensity) $406\left([\mathrm{M}+2]^{+}, 8\right), 404\left(\mathrm{M}^{+}, 25\right), 387$ (29), 285 (85), 265 (41), 253 (33), 204 (26), 203 (11), 132 (11), 105 (100); HRMS (EI) $m / z$ calcd. for $\mathrm{C}_{23} \mathrm{H}_{17} \mathrm{~N}_{2} \mathrm{O}_{3} \mathrm{Cl}\left(\mathrm{M}^{+}\right)$404.0928, found 404.0926.

3-(5-Bromo-2-nitrophenyl)-3-(1H-indol-3-yl)-1-phenylpropan-1-one (3d): Purified by column chromatography using 1:4 ethyl acetate and hexane. Concentration in vacuo give a pale brown solid with a melting point of $166-168{ }^{\circ} \mathrm{C} ;{ }^{1} \mathrm{H}-\mathrm{NMR}\left(\mathrm{CDCl}_{3}\right) \delta 8.14(\mathrm{~s}, 1 \mathrm{H}), 7.93(\mathrm{~d}, J=7.4 \mathrm{~Hz}, 2 \mathrm{H}), 7.66(\mathrm{~d}, J=8.6,1 \mathrm{H})$, 7.55-7.52 (m, 2H), 7.46-7.40 (m, 3H), $7.37(\mathrm{dd}, J=8.6,2.0 \mathrm{~Hz}, 1 \mathrm{H}), 7.29(\mathrm{~d}, J=8.2 \mathrm{~Hz}, 1 \mathrm{H}), 7.14(\mathrm{t}$, $J=7.3 \mathrm{~Hz}, 1 \mathrm{H}), 7.07(\mathrm{~d}, J=1.9 \mathrm{~Hz}, 1 \mathrm{H}), 7.01(\mathrm{t}, J=7.5 \mathrm{~Hz}, 1 \mathrm{H}), 5.70(\mathrm{t}, J=7.1 \mathrm{~Hz}, 1 \mathrm{H}), 3.85(\mathrm{dd}$, $J=17.3,6.8 \mathrm{~Hz}, 1 \mathrm{H}), 3.72(\mathrm{dd}, J=17.2,7.6 \mathrm{~Hz}, 1 \mathrm{H}) ;{ }^{13} \mathrm{C}-\mathrm{NMR}\left(\mathrm{CDCl}_{3}\right) \delta 197.3,149.0,141.4,136.8$, 136.7, 133.6, 133.2, 130.6, 128.9, 128.3, 127.5, 126.5, 126.1, 122.8, 122.2, 120.1, 119.4, 116.8, 111.5, 44.9, 32.8; MS (EI) $m / z$ (relative intensity) 450 ([M + 2] $\left.{ }^{+}, 23\right), 448\left(\mathrm{M}^{+}, 23\right), 431(26), 329(100), 311$ (63), 285 (30), 217 (30), 206 (54), 176 (16), 132 (27), 105 (95); HRMS (EI) m/z calcd. for $\mathrm{C}_{23} \mathrm{H}_{17} \mathrm{~N}_{2} \mathrm{O}_{3} \mathrm{Br}\left(\mathrm{M}^{+}\right)$ 448.0423 , found 448.0432 . 
1-(2-Chlorophenyl)-3-(1H-indol-3-yl)-3-(2-nitrophenyl)propan-1-one (3e): Yellow crystalline solid (crystallized from ethyl acetate and hexane) with a melting point of $114-116{ }^{\circ} \mathrm{C} ;{ }^{1} \mathrm{H}-\mathrm{NMR}\left(\mathrm{CDCl}_{3}\right) \delta 8.07(\mathrm{~s}, 1 \mathrm{H})$, $7.80(\mathrm{~d}, J=8.1 \mathrm{~Hz}, 1 \mathrm{H}), 7.43-7.21(\mathrm{~m}, 9 \mathrm{H}), 7.14(\mathrm{~m}, 2 \mathrm{H}), 6.98(\mathrm{t}, J=7.5 \mathrm{~Hz}, 1 \mathrm{H}), 5.55(\mathrm{t}, J=7.4 \mathrm{~Hz}, 1 \mathrm{H})$, $3.84(\mathrm{dd}, J=17.0,7.0 \mathrm{~Hz}, 1 \mathrm{H}), 3.77(\mathrm{dd}, J=17.0,8.1 \mathrm{~Hz}, 1 \mathrm{H}) ;{ }^{13} \mathrm{C}-\mathrm{NMR}\left(\mathrm{CDCl}_{3}\right) \delta 201.3,149.8,138.9$, 138.4, 136.7, 132.8, 131.9, 130.8, 130.6, 130.2, 129.0, 127.4, 127.1, 126.5, 124.5, 122.6, 122.5, 119.8, 119.3, 116.7, 111.4, 49.3, 33.3; MS (EI) $m / z$ (relative intensity) $406\left([\mathrm{M}+2]^{+}, 6\right), 404\left(\mathrm{M}^{+}, 18\right), 354(24), 269$ (44), 251 (74), 207 (46), 204 (42), 139 (100), 105 (76); HRMS (EI) m/z calcd for $\mathrm{C}_{23} \mathrm{H}_{17} \mathrm{~N}_{2} \mathrm{O}_{3} \mathrm{Cl}\left(\mathrm{M}^{+}\right)$ 404.0928, found 404.0929.

1-(2-Bromophenyl)-3-(1H-indol-3-yl)-3-(2-nitrophenyl)propan-1-one (3f): Purified by column chromatography using 1:5 ethyl acetate and hexane. After concentration in vacuo a yellow crystalline solid (from ethyl acetate and hexane) with a melting point of $132-134{ }^{\circ} \mathrm{C}$ was obtained; ${ }^{1} \mathrm{H}-\mathrm{NMR}\left(\mathrm{CDCl}_{3}\right) \delta 8.08(\mathrm{~s}$, $1 \mathrm{H}), 7.81(\mathrm{~d}, J=8.1 \mathrm{~Hz}, 1 \mathrm{H}), 7.54(\mathrm{~d}, J=7.6 \mathrm{~Hz}, 1 \mathrm{H}), 7.44-7.38(\mathrm{~m}, 2 \mathrm{H}), 7.33-7.30(\mathrm{~m}, 3 \mathrm{H}), 7.26-7.19$ $(\mathrm{m}, 3 \mathrm{H}), 7.15-7.12(\mathrm{~m}, 2 \mathrm{H}), 6.98(\mathrm{t}, J=7.7 \mathrm{~Hz}, 1 \mathrm{H}), 5.54(\mathrm{t}, J=7.4 \mathrm{~Hz}, 1 \mathrm{H}), 3.83(\mathrm{dd}, J=16.9,6.8 \mathrm{~Hz}$, 1H), $3.74(\mathrm{dd}, J=16.9,8.0 \mathrm{~Hz}, 1 \mathrm{H}) ;{ }^{13} \mathrm{C}-\mathrm{NMR}\left(\mathrm{CDCl}_{3}\right) \delta 202.0,149.9,141.1,138.3,136.7,133.8,132.9$, $131.8,130.3,128.7,127.6,127.5,126.5,124.5,122.7,122.5,119.8,119.3,118.7,116.6,111.4,49.0,33.4 ;$ MS (EI) $m / z$ (relative intensity) $450\left([\mathrm{M}+2]^{+}, 10\right), 448\left(\mathrm{M}^{+}, 10\right), 354(27), 251(60), 204$ (50), 183 (100), 155 (16), 132 (14), 105 (13); HRMS (EI) $m / z$ calcd. for $\mathrm{C}_{23} \mathrm{H}_{17} \mathrm{~N}_{2} \mathrm{O}_{3} \mathrm{Br}\left(\mathrm{M}^{+}\right)$448.0423, found 448.0420.

3-(1H-Indol-3-yl)-3-(2-nitrophenyl)-1-p-tolylpropan-1-one (3g): Purified by column chromatography using 1:5 ethyl acetate and hexane. After concentration in vacuo an orange oil was obtained; ${ }^{1} \mathrm{H}-\mathrm{NMR}$ $\left(\mathrm{CDCl}_{3}\right) \delta 8.01(\mathrm{~s}, 1 \mathrm{H}), 7.86(\mathrm{~d}, J=7.9 \mathrm{~Hz}, 2 \mathrm{H}), 7.79(\mathrm{~d}, J=8.0 \mathrm{~Hz}, 1 \mathrm{H}), 7.46-7.38(\mathrm{~m}, 3 \mathrm{H}), 7.31(\mathrm{t}$, $J=8.2 \mathrm{~Hz}, 2 \mathrm{H}), 7.24(\mathrm{~d}, J=8.0 \mathrm{~Hz}, 2 \mathrm{H}), 7.15(\mathrm{t}, J=7.3 \mathrm{~Hz}, 1 \mathrm{H}), 7.11(\mathrm{~s}, 1 \mathrm{H}), 7.00(\mathrm{t}, J=7.6 \mathrm{~Hz}, 1 \mathrm{H})$, $5.68(\mathrm{t}, J=7.2 \mathrm{~Hz}, 1 \mathrm{H}), 3.84(\mathrm{dd}, J=16.8,7.4 \mathrm{~Hz}, 1 \mathrm{H}), 3.77(\mathrm{dd}, J=17.2,7.8 \mathrm{~Hz}, 1 \mathrm{H}), 2.39(\mathrm{~s}, 3 \mathrm{H})$; ${ }^{13} \mathrm{C}-\mathrm{NMR}\left(\mathrm{CDCl}_{3}\right) \delta 197.4,150.1,144.3,139.0,136.8,134.4,132.7,130.1,129.5,128.4,127.3,126.6,124.4$, 122.5, 122.3, 119.8, 119.4, 117.4, 111.4, 44.9, 33.2, 21.8; MS (EI) $m / z$ (relative intensity) $384\left(\mathrm{M}^{+}, 46\right)$, 350 (39), 251 (100), 232 (40), 206 (38), 119 (63); HRMS (EI) $m / z$ calcd for $\mathrm{C}_{24} \mathrm{H}_{20} \mathrm{~N}_{2} \mathrm{O}_{3}\left(\mathrm{M}^{+}\right)$384.1474, found 384.1473 .

3-(1H-Indol-3-yl)-1-(4-methoxyphenyl)-3-(2-nitrophenyl)propan-1-one (3h): Purified by column chromatography using 1:5 ethyl acetate and hexane. After concentration in vacuo a yellow solid with a melting point of 207-209 ${ }^{\circ} \mathrm{C}$ was obtained; ${ }^{1} \mathrm{H}-\mathrm{NMR}\left(400 \mathrm{MHz}, \mathrm{DMSO}-d_{6}\right) \delta 10.96(\mathrm{~s}, 1 \mathrm{H}), 7.98(\mathrm{~d}, J=8.8 \mathrm{~Hz}, 2 \mathrm{H})$, $7.81(\mathrm{~d}, J=8.0 \mathrm{~Hz}, 1 \mathrm{H}), 7.59(\mathrm{~d}, J=7.2 \mathrm{~Hz}, 1 \mathrm{H}), 7.52(\mathrm{t}, J=7.3 \mathrm{~Hz}, 1 \mathrm{H}), 7.39-7.31(\mathrm{~m}, 4 \mathrm{H}), 7.05-7.00$ $(\mathrm{m}, 3 \mathrm{H}), 6.89(\mathrm{t}, J=7.4 \mathrm{~Hz}, 1 \mathrm{H}), 5.41(\mathrm{t}, J=7.2 \mathrm{~Hz}, 1 \mathrm{H}), 3.95(\mathrm{dd}, J=17.7,6.6 \mathrm{~Hz}, 1 \mathrm{H}), 3.83(\mathrm{~s}, 3 \mathrm{H}), 3.77$ $(\mathrm{dd}, J=17.7,8.0 \mathrm{~Hz}, 1 \mathrm{H}) ;{ }^{13} \mathrm{C}-\mathrm{NMR}\left(\mathrm{DMSO}-d_{6}\right) \delta 196.1,163.2,149.7,138.8,136.3,132.6,130.4,130.0$, $129.5,127.1,126.2,123.7,123.0,121.2,118.5,118.4,116.3,113.8,111.4,55.5,44.0,31.6$; MS (EI) $m / z$ (relative intensity) $400\left(\mathrm{M}^{+}, 25\right), 366$ (29), 250 (63), 222 (29), 206 (22), 135 (100); HRMS (EI) m/z calcd for $\mathrm{C}_{24} \mathrm{H}_{20} \mathrm{~N}_{2} \mathrm{O}_{4}\left(\mathrm{M}^{+}\right) 400.1423$, found 400.1428 .

1-(Benzo[d][1,3]dioxol-5-yl)-3-(1H-indol-3-yl)-3-(2-nitrophenyl)propan-1-one (3i): Purified by column chromatography using 1:5 ethyl acetate and hexane. After concentration in vacuo a pale yellow solid with a melting point of $150-152{ }^{\circ} \mathrm{C}$ was obtained; ${ }^{1} \mathrm{H}-\mathrm{NMR}\left(\mathrm{CDCl}_{3}\right) \delta 8.05(\mathrm{~s}, 1 \mathrm{H}), 7.78(\mathrm{dd}, J=8.0$, $0.8 \mathrm{~Hz}, 1 \mathrm{H}), 7.58(\mathrm{dd}, J=8.2,1.7 \mathrm{~Hz}, 1 \mathrm{H}), 7.44-7.37(\mathrm{~m}, 4 \mathrm{H}), 7.30-7.26(\mathrm{~m}, 2 \mathrm{H}), 7.13(\mathrm{dt}, J=7.2,0.5 \mathrm{~Hz}$, $1 \mathrm{H}), 7.08(\mathrm{~d}, J=2.0 \mathrm{~Hz}, 1 \mathrm{H}), 6.99(\mathrm{dt}, J=7.5,0.5 \mathrm{~Hz}, 1 \mathrm{H}), 6.81(\mathrm{~d}, J=8.1 \mathrm{~Hz}, 1 \mathrm{H}), 6.01(\mathrm{~s}, 2 \mathrm{H}), 5.65$ $(\mathrm{t}, J=7.2 \mathrm{~Hz}, 1 \mathrm{H}), 3.77(\mathrm{dd}, J=16.8,7.2 \mathrm{~Hz}, 1 \mathrm{H}), 3.70(\mathrm{dd}, J=17.0,7.5 \mathrm{~Hz}, 1 \mathrm{H}) ;{ }^{13} \mathrm{C}-\mathrm{NMR}\left(\mathrm{CDCl}_{3}\right) \delta$ 195.8, 152.1, 150.2, 148.4, 138.9, 136.8, 132.7, 131.8, 130.2, 127.3, 126.6, 124.6, 124.5, 122.5, 122.3, 119.9, $119.5,117.4,111.4,108.2,108.1,102.0,44.8,33.4$; $\mathrm{MS}$ (EI) $m / z$ (relative intensity) $414\left(\mathrm{M}^{+}, 18\right), 380(17)$, 251 (65), 207 (20), 148 (100); HRMS (EI) m/ $z$ calcd for $\mathrm{C}_{24} \mathrm{H}_{18} \mathrm{~N}_{2} \mathrm{O}_{5}\left(\mathrm{M}^{+}\right)$414.1216, found 414.1209.

3-(1H-Indol-3-yl)-1-(naphthalen-2-yl)-3-(2-nitrophenyl)propan-1-one (3j): Purified by column chromatography using 1:5 ethyl acetate and hexane. After concentration in vacuo a yellow solid with a melting point of $185-187{ }^{\circ} \mathrm{C}$ was isolated; ${ }^{1} \mathrm{H}-\mathrm{NMR}\left(\mathrm{DMSO}-\mathrm{d}_{6}\right) \delta 10.98(\mathrm{~s}, 1 \mathrm{H}), 8.79(\mathrm{~s}, 1 \mathrm{H}), 8.12(\mathrm{~d}, J=7.8 \mathrm{~Hz}, 1 \mathrm{H})$, $7.99-7.96(\mathrm{~m}, 3 \mathrm{H}), 7.84(\mathrm{dd}, J=8.1,1.1 \mathrm{~Hz}, 1 \mathrm{H}), 7.67-7.62(\mathrm{~m}, 3 \mathrm{H}), 7.54(\mathrm{dt}, J=7.7,1.1 \mathrm{~Hz}, 1 \mathrm{H}), 7.44$ 
$(\mathrm{d}, J=2.2 \mathrm{~Hz}, 1 \mathrm{H}), 7.42-7.38(\mathrm{~m}, 2 \mathrm{H}), 7.33(\mathrm{~d}, J=8.1 \mathrm{~Hz}, 1 \mathrm{H}), 7.04(\mathrm{dt}, J=7.1,0.8 \mathrm{~Hz}, 1 \mathrm{H}), 6.90(\mathrm{dt}$, $J=7.4,0.6 \mathrm{~Hz}, 1 \mathrm{H}), 5.49(\mathrm{t}, J=7.2 \mathrm{~Hz}, 1 \mathrm{H}), 4.19(\mathrm{dd}, J=17.9,6.8 \mathrm{~Hz}, 1 \mathrm{H}), 3.99(\mathrm{dd}, J=17.8,7.7 \mathrm{~Hz}$, 1H); ${ }^{13}$ C-NMR (DMSO- $d_{6}$ ) $\delta$ 197.7, $149.7,138.8,136.4,135.1,133.7,132.7,132.2,130.1,130.1,129.6$, 128.7, 128.2, 127.6, 127.2, 126.9, 126.2, 123.8, 123.5, 123.1, 121.2, 118.6, 118.4, 116.2, 111.5, 44.5, 31.7; MS (EI) $m / z$ (relative intensity) $420\left(\mathrm{M}^{+}, 5\right), 251$ (19), 155 (100), 127 (36); HRMS (EI) $m / z$ calcd for $\mathrm{C}_{27} \mathrm{H}_{20} \mathrm{~N}_{2} \mathrm{O}_{3}\left(\mathrm{M}^{+}\right) 420.1474$, found 420.1465 .

3-(1H-Indol-3-yl)-3-(2-nitrophenyl)-1-(thiophen-2-yl)propan-1-one (3k): Purified by column chromatography using 1:5 ethyl acetate and hexane. After concentration in vacuo a pale brown solid with a melting point of $146-148{ }^{\circ} \mathrm{C}$ was obtained; ${ }^{1} \mathrm{H}-\mathrm{NMR}\left(\mathrm{CDCl}_{3}\right) \delta 8.04(\mathrm{~s}, 1 \mathrm{H}), 7.81-7.79(\mathrm{~m}, 2 \mathrm{H}), 7.61(\mathrm{~d}$, $J=4.7 \mathrm{~Hz}, 1 \mathrm{H}), 7.47-7.40(\mathrm{~m}, 2 \mathrm{H}), 7.36-7.28(\mathrm{~m}, 3 \mathrm{H}), 7.17-7.10(\mathrm{~m}, 3 \mathrm{H}), 7.00(\mathrm{t}, J=7.5 \mathrm{~Hz}, 1 \mathrm{H}), 5.67$ $(\mathrm{t}, J=7.4 \mathrm{~Hz}, 1 \mathrm{H}), 3.79(\mathrm{dd}, J=14.5,5.8 \mathrm{~Hz}, 1 \mathrm{H}), 3.74(\mathrm{dd}, J=14.6,5.6 \mathrm{~Hz}, 1 \mathrm{H}) ;{ }^{13} \mathrm{C}-\mathrm{NMR}\left(\mathrm{CDCl}_{3}\right) \delta$ 190.7, 150.0, 144.1, 138.6, 136.7, 134.1, 132.8, 132.3, 130.3, 128.4, 127.5, 126.6, 124.5, 122.5, 119.8, 119.3, 116.9, 111.5, 45.6, 33.6; MS (EI) $m / z$ (relative intensity) 251 (22), 204 (25), 111 (100); HRMS (EI) $m / z$ calcd for $\mathrm{C}_{21} \mathrm{H}_{26} \mathrm{~N}_{2} \mathrm{O}_{3} \mathrm{~S}\left(\mathrm{M}^{+}\right)$376.0882, found 376.0880 .

3-(5-Fluoro-1H-indol-3-yl)-3-(2-nitrophenyl)-1-phenylpropan-1-one (31): Purified by column chromatography using 1:4 ethyl acetate and hexane. After concentration in vacuo a yellow solid with a melting point of $192-194{ }^{\circ} \mathrm{C}$ was obtained; ${ }^{1} \mathrm{H}-\mathrm{NMR}$ (DMSO- $\left.d_{6}\right) \delta 11.10(\mathrm{~s}, 1 \mathrm{H}), 7.99(\mathrm{~d}, J=7.7 \mathrm{~Hz}, 2 \mathrm{H}), 7.83$ $(\mathrm{d}, J=8.1 \mathrm{~Hz}, 1 \mathrm{H}), 7.63-7.61(\mathrm{~m}, 2 \mathrm{H}), 7.56-7.48(\mathrm{~m}, 4 \mathrm{H}), 7.38(\mathrm{t}, J=7.8 \mathrm{~Hz}, 1 \mathrm{H}), 7.33(\mathrm{dd}, J=8.8$, $4.6 \mathrm{~Hz}, 1 \mathrm{H}), 7.15(\mathrm{dd}, J=10.2,2.0 \mathrm{~Hz}, 1 \mathrm{H}), 6.88(\mathrm{dt}, J=9.2,2.2 \mathrm{~Hz}, 1 \mathrm{H}), 5.37(\mathrm{t}, J=7.3 \mathrm{~Hz}, 1 \mathrm{H}), 4.00$ $(\mathrm{dd}, J=18.1,6.2 \mathrm{~Hz}, 1 \mathrm{H}), 3.92(\mathrm{dd}, J=18.1,8.1 \mathrm{~Hz}, 1 \mathrm{H}) ;{ }^{13} \mathrm{C}-\mathrm{NMR}\left(\right.$ DMSO- $\left.d_{6}\right) \delta 197.8,156.7(\mathrm{~d}$, $\left.J_{C-F}=230 \mathrm{~Hz}\right), 149.8,138.5,136.4,133.3,133.1,132.7,129.9,128.6,128.0,127.2,126.4\left(\mathrm{~d}, J_{C-F}=10 \mathrm{~Hz}\right)$, 125.3, 123.8, $116.6\left(\mathrm{~d}, J_{C-F}=5 \mathrm{~Hz}\right), 112.5\left(\mathrm{~d}, J_{C-F}=10 \mathrm{~Hz}\right), 109.4\left(\mathrm{~d}, J_{C-F}=26 \mathrm{~Hz}\right), 103.2\left(\mathrm{~d}, J_{C-F}=\right.$ $23 \mathrm{~Hz}$ ); MS (EI) $m / z$ (relative intensity) 388 (M+ $\left.{ }^{+}, 29\right), 371$ (25), 269 (92), 222 (56); HRMS (EI) $m / z$ calcd for $\mathrm{C}_{23} \mathrm{H}_{17} \mathrm{~N}_{2} \mathrm{O}_{3} \mathrm{~F}\left(\mathrm{M}^{+}\right)$388.1223, found 388.1227.

3-(5-Chloro-1H-indol-3-yl)-3-(2-nitrophenyl)-1-phenylpropan-1-one (3m): Purified by column chromatography using 1:4 ethyl acetate and hexane. After concentration in vacuo a pale yellow solid with a melting point of $198-200{ }^{\circ} \mathrm{C}$ was obtained; ${ }^{1} \mathrm{H}-\mathrm{NMR}\left(\mathrm{DMSO}_{6} \mathrm{~d}_{6}\right) \delta 11.22(\mathrm{~s}, 1 \mathrm{H}), 7.99(\mathrm{~d}, J=7.4 \mathrm{~Hz}, 2 \mathrm{H}), 7.84$ $(\mathrm{d}, J=8.0 \mathrm{~Hz}, 1 \mathrm{H}), 7.64-7.61(\mathrm{~m}, 2 \mathrm{H}), 7.56-7.48(\mathrm{~m}, 4 \mathrm{H}), 7.46(\mathrm{~d}, J=1.5 \mathrm{~Hz}, 1 \mathrm{H}), 7.40-7.34(\mathrm{~m}, 2 \mathrm{H})$, $7.04(\mathrm{dd}, J=8.6,1.8 \mathrm{~Hz}, 1 \mathrm{H}), 5.38(\mathrm{t}, J=7.2 \mathrm{~Hz}, 1 \mathrm{H}), 4.00(\mathrm{dd}, J=18.2,6.4 \mathrm{~Hz}, 1 \mathrm{H}), 3.92(\mathrm{dd}, J=18.2$, $8.4 \mathrm{~Hz}, 1 \mathrm{H}) ;{ }^{13} \mathrm{C}-\mathrm{NMR}$ (DMSO- $\left.d_{6}\right) \delta 197.7,149.8,138.5,136.4,134.8,133.3,132.8,130.0,128.6,127.3$, $127.3,125.1,123.9,123.3,121.2,117.7,116.2,113.1,44.5,31.3$; MS (EI) $m / z$ (relative intensity) 406 $\left([\mathrm{M}+2]^{+}, 10\right), 404\left(\mathrm{M}^{+}, 31\right), 387$ (25), 285 (92), 265 (30), 253 (29), 205 (32), 204 (19), 105 (94), 84 (100); HRMS (EI) $m / z$ calcd for $\mathrm{C}_{23} \mathrm{H}_{17} \mathrm{~N}_{2} \mathrm{O}_{3} \mathrm{Cl}\left(\mathrm{M}^{+}\right) 404.0928$, found 404.0930 .

3-(5-Bromo-1H-indol-3-yl)-3-(2-nitrophenyl)-1-phenylpropan-1-one (3n): Purified by column chromatography using 1:5 ethyl acetate and hexane. Concentration in vacuo gave a brown solid with a melting point of $152-154{ }^{\circ} \mathrm{C} ;{ }^{1} \mathrm{H}-\mathrm{NMR}\left(\mathrm{DMSO}-d_{6}\right) \delta 11.25(\mathrm{~s}, 1 \mathrm{H}), 8.00(\mathrm{~d}, J=7.9 \mathrm{~Hz}, 2 \mathrm{H}), 7.84(\mathrm{~d}, J=8.1 \mathrm{~Hz}, 1 \mathrm{H})$, $7.63-7.60(\mathrm{~m}, 3 \mathrm{H}), 7.56-7.52(\mathrm{~m}, 2 \mathrm{H}), 7.50(\mathrm{t}, J=7.6 \mathrm{~Hz}, 2 \mathrm{H}), 7.38(\mathrm{t}, J=8.0 \mathrm{~Hz}, 1 \mathrm{H}), 7.32(\mathrm{~d}, J=8.6 \mathrm{~Hz}$, $1 \mathrm{H}), 7.16(\mathrm{~d}, J=8.6 \mathrm{~Hz}, 1 \mathrm{H}), 5.40(\mathrm{t}, J=7.2,1 \mathrm{H}), 4.01(\mathrm{dd}, J=18.2,6.0 \mathrm{~Hz}, 1 \mathrm{H}), 3.92(\mathrm{dd}, J=18.2$, $8.4 \mathrm{~Hz}, 1 \mathrm{H}$ ); ${ }^{13} \mathrm{C}-\mathrm{NMR}$ (DMSO- $\left.d_{6}\right) \delta 197.7,149.7,138.4,136.4,135.0,133.3,132.8,129.9,128.6,128.0$, 128.0, 127.3, 124.9, 123.8, 123.7, 120.7, 116.1, 113.5, 111.2, 44.5, 31.2; MS (EI) $m / z$ (relative intensity) $450\left([\mathrm{M}+2]^{+}, 7\right), 448\left(\mathrm{M}^{+}, 7\right), 431$ (7), 329 (26), 311 (23), 284 (16), 217 (13), 205 (23), 105 (100); HRMS (EI) $m / z$ calcd for $\mathrm{C}_{23} \mathrm{H}_{17} \mathrm{~N}_{2} \mathrm{O}_{3} \mathrm{Br}\left(\mathrm{M}^{+}\right) 448.0423$, found 448.0414 .

3-(5-Methoxy-1H-indol-3-yl)-3-(2-nitrophenyl)-1-phenylpropan-1-one (3o): Purified by column chromatography using 1:5 ethyl acetate and hexane. After concentration in vacuo a green oil was obtained; ${ }^{1} \mathrm{H}-\mathrm{NMR}$ $\left(\mathrm{CDCl}_{3}\right) \delta 8.17(\mathrm{~s}, 1 \mathrm{H}), 7.92(\mathrm{~s}, 1 \mathrm{H}), 7.89(\mathrm{~d}, J=1.3 \mathrm{~Hz}, 1 \mathrm{H}), 7.71(\mathrm{dd}, J=8.0,1.1 \mathrm{~Hz}, 1 \mathrm{H}), 7.49(\mathrm{t}, J=7.5$ $\mathrm{Hz}, 1 \mathrm{H}), 7.37(\mathrm{~m}, 3 \mathrm{H}), 7.31(\mathrm{dt}, J=7.7,1.0 \mathrm{~Hz}, 1 \mathrm{H}), 7.19(\mathrm{dt}, J=7.5,1.2 \mathrm{~Hz}, 1 \mathrm{H}), 7.08(\mathrm{~d}, J=8.8 \mathrm{~Hz}$, $1 \mathrm{H}), 6.98(\mathrm{~d}, J=2.1 \mathrm{~Hz}, 1 \mathrm{H}), 6.88(\mathrm{~d}, J=2.4 \mathrm{~Hz}, 1 \mathrm{H}), 6.73(\mathrm{dd}, J=8.8,2.4 \mathrm{~Hz}, 1 \mathrm{H}), 5.61(\mathrm{t}, J=7.2 \mathrm{~Hz}$, $1 \mathrm{H}), 3.79(\mathrm{dd}, J=17.2,6.9 \mathrm{~Hz}, 1 \mathrm{H}), 3.72(\mathrm{dd}, J=17.2,7.5 \mathrm{~Hz}, 1 \mathrm{H}), 3.66(\mathrm{~s}, 3 \mathrm{H}) ;{ }^{13} \mathrm{C}-\mathrm{NMR}\left(\mathrm{CDCl}_{3}\right) \delta$ 
197.7, 154.3, 150.4, 138.8, 136.8, 133.5, 132.7, 131.8, 130.2, 128.9, 128.3, 127.4, 127.1, 124.4, 122.7, 117.4, 112.9, 112.1, 101.2, 55.9, 45.0, 33.0, MS (EI) $m / z$ (relative intensity) $400\left(\mathrm{M}^{+}, 32\right), 383(25), 281(68)$, 261 (39), 249 (24), 204 (16), 162 (12), 105 (100); HRMS (EI) $m / z$ calcd for $\mathrm{C}_{24} \mathrm{H}_{20} \mathrm{~N}_{2} \mathrm{O}_{4}\left(\mathrm{M}^{+}\right)$400.1423, found 400.1431 .

3-(7-Methyl-1H-indol-3-yl)-3-(2-nitrophenyl)-1-phenylpropan-1-one (3p): Purified by column chromatography using 1:5 ethyl acetate and hexane. After concentration in vacuo a pale green solid with a melting point of $139-141{ }^{\circ} \mathrm{C}$ was obtained; ${ }^{1} \mathrm{H}-\mathrm{NMR}\left(\mathrm{CDCl}_{3}\right) \delta 7.97-7.95(\mathrm{~m}, 3 \mathrm{H}), 7.80(\mathrm{~d}, J=8.1 \mathrm{~Hz}, 1 \mathrm{H})$, $7.55(\mathrm{t}, J=7.36 \mathrm{~Hz}, 1 \mathrm{H}), 7.46-7.39(\mathrm{~m}, 4 \mathrm{H}), 7.31-7.23(\mathrm{~m}, 2 \mathrm{H}), 7.11(\mathrm{~d}, J=1.8 \mathrm{~Hz}, 1 \mathrm{H}), 6.96-6.91(\mathrm{~m}$, $2 \mathrm{H}), 5.67(\mathrm{t}, J=7.2 \mathrm{~Hz}, 1 \mathrm{H}), 3.87(\mathrm{dd}, J=16.7,7.2 \mathrm{~Hz}, 1 \mathrm{H}), 3.80(\mathrm{dd}, J=16.7,6.6 \mathrm{~Hz}, 1 \mathrm{H}), 2.45(\mathrm{~s}, 3 \mathrm{H})$; ${ }^{13} \mathrm{C}-\mathrm{NMR}\left(\mathrm{CDCl}_{3}\right) \delta 197.8,150.1,138.9,136.8,136.3,133.4,132.8,130.1,128.8,128.3,127.3,126.1,124.5$, 123.1, 122.0, 120.6, 120.1, 117.8, 117.2, 45.0, 33.3, 16.7; MS (EI) $m / z$ (relative intensity) $384\left(\mathrm{M}^{+}, 23\right), 367$ (28), 265 (60), 245 (41), 219 (32), 204 (12), 146 (10), 105 (100); HRMS (EI) $m / z$ calcd for $\mathrm{C}_{24} \mathrm{H}_{20} \mathrm{~N}_{2} \mathrm{O}_{3}$ $\left(\mathrm{M}^{+}\right)$384.1474, found 384.1476.

3-(1-Methyl-1H-indol-3-yl)-3-(2-nitrophenyl)-1-phenylpropan-1-one (3q): Purified by column chromatography using 1:5 ethyl acetate and hexane. After concentration in vacuo a yellow solid with a melting point of $166-168{ }^{\circ} \mathrm{C}$ was obtained; ${ }^{1} \mathrm{H}-\mathrm{NMR}\left(\mathrm{CDCl}_{3}\right) \delta 7.96(\mathrm{~d}, J=7.7 \mathrm{~Hz}, 2 \mathrm{H}), 7.80(\mathrm{~d}, J=8.1 \mathrm{~Hz}, 1 \mathrm{H}), 7.55$ $(\mathrm{t}, J=7.2 \mathrm{~Hz}, 1 \mathrm{H}), 7.47-7.39(\mathrm{~m}, 5 \mathrm{H}), 7.30-7.24(\mathrm{~m}, 2 \mathrm{H}), 7.18(\mathrm{t}, J=7.2 \mathrm{~Hz}, 1 \mathrm{H}), 7.00(\mathrm{t}, J=7.3 \mathrm{~Hz}, 1 \mathrm{H})$, $6.95(\mathrm{~s}, 1 \mathrm{H}), 5.67(\mathrm{t}, J=7.2 \mathrm{~Hz}, 1 \mathrm{H}), 3.86(\mathrm{dd}, J=16.9,7.2 \mathrm{~Hz}, 1 \mathrm{H}), 3.80(\mathrm{dd}, J=16.8,6.8 \mathrm{~Hz}, 1 \mathrm{H}), 3.74$ $(\mathrm{s}, 3 \mathrm{H}) ;{ }^{13} \mathrm{C}-\mathrm{NMR}\left(\mathrm{CDCl}_{3}\right) \delta 197.6,150.1,139.1,137.5,136.9,133.4,132.7,130.1,128.8,128.3,127.3$, 127.0, 127.0, 124.5, 122.2, 119.6, 119.4, 115.9, 109.5, 45.2, 33.1, 33.0; MS (EI) $m / z$ (relative intensity) 384 $\left(\mathrm{M}^{+}, 24\right), 367$ (55), 265 (100), 248 (45), 218 (58), 217 (23), 146 (20), 105 (58); HRMS (EI) $m / z$ calcd for $\mathrm{C}_{24} \mathrm{H}_{20} \mathrm{~N}_{2} \mathrm{O}_{3}\left(\mathrm{M}^{+}\right)$384.1474, found 384.1478.

3-(2-Methyl-1H-indol-3-yl)-3-(2-nitrophenyl)-1-phenylpropan-1-one (3r): Purified by column chromatography using 1:5 ethyl acetate and hexane. Concentration in vacuo gave a yellow solid with a melting point of $129-131{ }^{\circ} \mathrm{C} ;{ }^{1} \mathrm{H}-\mathrm{NMR}\left(\mathrm{CDCl}_{3}\right) \delta 7.88(\mathrm{~s}, 1 \mathrm{H}), 7.86(\mathrm{~d}, J=1.0 \mathrm{~Hz}, 1 \mathrm{H}), 7.77(\mathrm{~s}, 1 \mathrm{H}), 7.72(\mathrm{~d}, J=7.9 \mathrm{~Hz}$, $1 \mathrm{H}), 7.68(\mathrm{~d}, J=8.0 \mathrm{~Hz}, 1 \mathrm{H}), 7.53-7.47(\mathrm{~m}, 2 \mathrm{H}), 7.38(\mathrm{t}, J=7.8 \mathrm{~Hz}, 2 \mathrm{H}), 7.31(\mathrm{t}, J=8.0 \mathrm{~Hz}, 2 \mathrm{H}), 7.20(\mathrm{~d}$, $J=80 \mathrm{~Hz}, 1 \mathrm{H}), 7.04(\mathrm{t}, J=7.2 \mathrm{~Hz}, 1 \mathrm{H}), 6.95(\mathrm{t}, J=7.3 \mathrm{~Hz}, 1 \mathrm{H}), 5.71(\mathrm{t}, J=7.2 \mathrm{~Hz}, 1 \mathrm{H}), 3.95(\mathrm{dd}, J=16.9$, $7.8 \mathrm{~Hz}, 1 \mathrm{H}), 3.84(\mathrm{dd}, \mathrm{J}=16.9,6.7 \mathrm{~Hz}, 1 \mathrm{H}) ;{ }^{13} \mathrm{C}-\mathrm{NMR}\left(\mathrm{CDCl}_{3}\right) \delta 198.0,150.4,138.6,137.0,135.7,133.3$, $133.1,132.3,129.3,128.8,128.2,127.6,127.3,124.9,121.1,119.7,118.6,111.5,110.8,43.3,33.1,12.2$; MS (EI) $m / z$ (relative intensity) $384\left(\mathrm{M}^{+}, 53\right), 367$ (17), 265(100), 247 (92), 218 (60), 217 (46), 146 (67), 105 (55); HRMS (EI) $m / z$ calcd for $\mathrm{C}_{24} \mathrm{H}_{20} \mathrm{~N}_{2} \mathrm{O}_{3}\left(\mathrm{M}^{+}\right) 384.1474$, found 384.1481 .

3-(2-Nitrophenyl)-1-phenyl-3-(2-phenyl-1H-indol-3-yl)propan-1-one (3s): Purified by column chromatography using 1:5 ethyl acetate and hexane. After concentration in vacuo a deep brown oil was obtained; IR (KBr): 3390, 3059, 1682, 1601, 1526, 1451, 1351, 741, $698 \mathrm{~cm}^{-1} .{ }^{1} \mathrm{H}-\mathrm{NMR}\left(\mathrm{CDCl}_{3}\right) \delta 8.15(\mathrm{~s}, 1 \mathrm{H}), 7.74$ (d, $J=7.4 \mathrm{~Hz}, 2 \mathrm{H}), 7.67(\mathrm{t}, J=7.1 \mathrm{~Hz}, 2 \mathrm{H}), 7.60(\mathrm{~d}, J=7.9 \mathrm{~Hz}, 1 \mathrm{H}), 7.43(\mathrm{t}, J=7.4 \mathrm{~Hz}, 1 \mathrm{H}), 7.36-7.20(\mathrm{~m}$, $10 \mathrm{H}), 7.11(\mathrm{t}, J=7.2 \mathrm{~Hz}, 1 \mathrm{H}), 7.04(\mathrm{t}, J=7.5 \mathrm{~Hz}, 1 \mathrm{H}), 5.80(\mathrm{t}, J=7.3 \mathrm{~Hz}, 1 \mathrm{H}), 4.05(\mathrm{dd}, J=17.4,8.5 \mathrm{~Hz}$, $1 \mathrm{H}), 3.78(\mathrm{dd}, J=17.3,6.1 \mathrm{~Hz}, 1 \mathrm{H}) ;{ }^{13} \mathrm{C}-\mathrm{NMR}\left(\mathrm{CDCl}_{3}\right) \delta 197.6,149.2,139.0,136.6,136.5,136.0,132.9$, 132.5, 132.5, 130.1, 128.6, 128.5, 128.4, 128.1, 127.9, 127.8, 127.2, 124.5, 121.9, 119.9, 119.8, 111.8, 111.7, 44.1, 33.8; HRMS (ESI) $m / z$ calcd for $\mathrm{C}_{29} \mathrm{H}_{22} \mathrm{~N}_{2} \mathrm{O}_{3} \mathrm{Na}\left([\mathrm{M}+\mathrm{Na}]^{+}\right.$) 469.1528, found 469.1519.

3-(1H-Indol-3-yl)-3-(3-methyl-2-nitrophenyl)-1-phenylpropan-1-one (3t): Purified by column chromatography using 1:5 ethyl acetate and hexane. After concentration in vacuo a pale pink solid with a melting point of $191-193{ }^{\circ} \mathrm{C}$ was obtained; ${ }^{1} \mathrm{H}-\mathrm{NMR}\left(\mathrm{CDCl}_{3}\right) \delta 8.00(\mathrm{~s}, 1 \mathrm{H}), 7.93(\mathrm{~d}, J=7.6 \mathrm{~Hz}, 2 \mathrm{H}), 7.54(\mathrm{t}, J=$ $7.3 \mathrm{~Hz}, 1 \mathrm{H}), 7.45-7.38(\mathrm{~m}, 3 \mathrm{H}), 7.26(\mathrm{t}, J=8.1 \mathrm{~Hz}, 1 \mathrm{H}), 7.21-7.20(\mathrm{~m}, 2 \mathrm{H}), 7.14-7.10(\mathrm{~m}, 2 \mathrm{H}), 7.02-6.98$ $(\mathrm{m}, 2 \mathrm{H}), 5.07(\mathrm{t}, J=6.8 \mathrm{~Hz}, 1 \mathrm{H}), 3.81(\mathrm{dd}, J=16.8,8.5 \mathrm{~Hz}, 1 \mathrm{H}), 3.69(\mathrm{dd}, J=16.8,6.0 \mathrm{~Hz}, 1 \mathrm{H}), 2.31$ $(\mathrm{s}, 3 \mathrm{H}) ;{ }^{13} \mathrm{C}-\mathrm{NMR}\left(\mathrm{CDCl}_{3}\right) \delta 197.6,151.5,136.9,136.8,135.9,133.4,130.2,129.7,129.6,128.9,128.4$, 127.0, 126.6, 122.6, 122.3, 119.9, 119.5, 117.0, 111.3, 45.1, 34.0, 17.7; MS (EI) $m / z$ (relative intensity) 384 $\left(\mathrm{M}^{+}, 22\right), 367$ (25), 265 (23), 247 (60), 221 (42), 204 (18); HRMS (EI) $m / z$ calcd for $\mathrm{C}_{24} \mathrm{H}_{20} \mathrm{~N}_{2} \mathrm{O}_{3}\left(\mathrm{M}^{+}\right)$ 384.1474 , found 384.1476 . 
3-(2,5-Dimethyl-1H-indol-3-yl)-3-(2-nitrophenyl)-1-phenylpropan-1-one (3u): Purified by column chromatography using 1:4 ethyl acetate and hexane. After concentration in vacuo a green solid with a melting point of $119-121{ }^{\circ} \mathrm{C}$ was obtained; ${ }^{1} \mathrm{H}-\mathrm{NMR}\left(\mathrm{CDCl}_{3}\right) \delta 7.88(\mathrm{dd}, J=7.8,1.3 \mathrm{~Hz}, 2 \mathrm{H})$, 7.71-7.67 (m, 3H), 7.54-7.48 (m, 2H), $7.40(\mathrm{t}, J=7.9 \mathrm{~Hz}, 2 \mathrm{H}), 7.32(\mathrm{dt}, J=8.4,1.2 \mathrm{~Hz}, 1 \mathrm{H}), 7.11-7.09(\mathrm{~m}$, $2 \mathrm{H}), 6.87(\mathrm{~d}, J=8.1 \mathrm{~Hz}, 1 \mathrm{H}), 5.69(\mathrm{t}, J=7.1 \mathrm{~Hz}, 1 \mathrm{H}), 3.94(\mathrm{dd}, J=17.0,7.6 \mathrm{~Hz}, 1 \mathrm{H}), 3.84(\mathrm{dd}, J=17.0$, $6.8 \mathrm{~Hz}, 1 \mathrm{H}), 2.34(\mathrm{~s}, 3 \mathrm{H}), 2.33(\mathrm{~s}, 3 \mathrm{H}) ;{ }^{13} \mathrm{C}-\mathrm{NMR}\left(\mathrm{CDCl}_{3}\right) \delta 198.0,150.3,138.7,137.1,133.9,133.2,133.2$, $132.3,129.5,128.7,128.7,128.2,127.9,127.2,124.8,122.6,118.5,111.0,110.5,43.4,33.1,21.9,12.3$; MS (EI) $m / z$ (relative intensity) $398\left(\mathrm{M}^{+}, 25\right), 262$ (53), 261 (36), 207 (33), 160 (48), 105 (100); HRMS (EI) $m / z$ calcd for $\mathrm{C}_{25} \mathrm{H}_{22} \mathrm{~N}_{2} \mathrm{O}_{3}\left(\mathrm{M}^{+}\right) 398.1630$, found 398.1629.

3-(2,5-Dimethyl-1H-indol-3-yl)-3-(3-methyl-2-nitrophenyl)-1-phenylpropan-1-one (3v): Purified by column chromatography using 1:4 ethyl acetate and hexane. After concentration in vacuo a pale yellow solid with a melting point of $173-175{ }^{\circ} \mathrm{C}$ was obtained; ${ }^{1} \mathrm{H}-\mathrm{NMR}\left(\mathrm{CDCl}_{3}\right) \delta 77.88-7.86(\mathrm{~m}, 2 \mathrm{H}), 7.63(\mathrm{~s}, 1 \mathrm{H})$, 7.55-7.50 (m, 2H), $7.40(\mathrm{t}, J=7.8 \mathrm{~Hz}, 2 \mathrm{H}), 7.31(\mathrm{t}, J=7.8 \mathrm{~Hz}, 1 \mathrm{H}), 7.20(\mathrm{~s}, 1 \mathrm{H}), 7.13(\mathrm{~d}, J=7.6 \mathrm{~Hz}, 1 \mathrm{H})$, $7.09(\mathrm{~d}, J=8.2 \mathrm{~Hz}, 1 \mathrm{H}), 6.87(\mathrm{~d}, J=8.2 \mathrm{~Hz}, 1 \mathrm{H}), 5.18(\mathrm{dd}, J=8.2,6.2 \mathrm{~Hz}, 1 \mathrm{H}), 3.96(\mathrm{dd}, J=16.9,8.4 \mathrm{~Hz}$, $1 \mathrm{H}), 3.80(\mathrm{dd}, J=16.9,6.2 \mathrm{~Hz}, 1 \mathrm{H}), 2.35(\mathrm{~s}, 3 \mathrm{H}), 2.32(\mathrm{~s}, 3 \mathrm{H}), 2.23(\mathrm{~s}, 3 \mathrm{H}) ;{ }^{13} \mathrm{C}-\mathrm{NMR}\left(\mathrm{CDCl}_{3}\right) \delta 197.9$, $151.8,137.1,135.7,133.9,133.2,133.0,130.0,129.9,129.4,128.7,128.5,128.2,127.6,126.2,122.5,118.5$, 110.7, $110.4,43.2,33.0,21.9,17.6,12.1$; MS (EI) $m / z$ (relative intensity) $412\left(\mathrm{M}^{+}, 25\right), 275$ (39), 247 (16), 221 (50), 160 (37), 105 (100); HRMS (EI) $m / z$ calcd for $\mathrm{C}_{26} \mathrm{H}_{24} \mathrm{~N}_{2} \mathrm{O}_{3}\left(\mathrm{M}^{+}\right)$412.1787, found 412.1780.

\subsection{General Procedure for Reductive Cyclization (Synthesis of $\mathbf{4 a - 4 u}$ )}

To a stirred solution of 3a $(1 \mathrm{mmol})$ in ethanol $(10 \mathrm{~mL})$, powdered $\mathrm{Fe}(6 \mathrm{mmol})$ and $\mathrm{HCl}$ (1 mmol) were added and the reaction mixture was kept stirring at reflux until TLC analysis showed complete consumption of 3a. Then, the reaction mixture was quenched by saturated aq. $\mathrm{NaHCO}_{3}$, filtered by celite and concentrated, then the residue was extracted with ethyl acetate three times (10 mL each time). The combined organic layers were dried over magnesium sulfate, filtered and concentrated. The residue was purified by recrystallization or flash chromatography (EtOAc/hexane) to afford the final product 4a. (The ${ }^{1} \mathrm{H}-,{ }^{13} \mathrm{C}-\mathrm{NMR}$ spectra of the compounds $(\mathbf{4 a}-\mathbf{4 u})$ was showed in Supplementary).

4-(1H-Indol-3-yl)-2-phenylquinoline (4a): Pale yellow crystalline solid (crystallized from ethyl acetate and hexane) with a melting point of $229-231^{\circ} \mathrm{C}$; IR (KBr): 3200, 3050, 1591, 1546, 1498, 1237, 828, $741 \mathrm{~cm}^{-1}$. ${ }^{1} \mathrm{H}-\mathrm{NMR}\left(\mathrm{DMSO}-\mathrm{d}_{6}\right) \delta 11.78(\mathrm{~s}, 1 \mathrm{H}), 8.31(\mathrm{~d}, J=7.2 \mathrm{~Hz}, 2 \mathrm{H}), 8.17-8.13(\mathrm{~m}, 3 \mathrm{H}), 7.90(\mathrm{~d}$, $J=1.8 \mathrm{~Hz}, 1 \mathrm{H}), 7.79(\mathrm{t}, J=7.3 \mathrm{~Hz}, 1 \mathrm{H}), 7.59-7.48(\mathrm{~m}, 6 \mathrm{H}), 7.23(\mathrm{t}, J=7.3 \mathrm{~Hz}, 1 \mathrm{H}), 7.11(\mathrm{t}, J=7.5 \mathrm{~Hz}$, $1 \mathrm{H}) ;{ }^{13} \mathrm{C}-\mathrm{NMR}\left(\mathrm{DMSO}-d_{6}\right) \delta 155.9,148.5,142.9,139.0,136.6,129.7,129.6,129.4,128.8,127.3,126.6$, $126.2,126.1,126.0,125.7,121.9,120.0,119.1,118.5,112.2,112.0 ; \mathrm{MS}$ (EI) $\mathrm{m} / \mathrm{z}$ (relative intensity) 320 $\left(\mathrm{M}^{+}, 100\right)$; HRMS (EI) $m / z$ calcd for $\mathrm{C}_{23} \mathrm{H}_{16} \mathrm{~N}_{2}\left(\mathrm{M}^{+}\right) 320.1313$, found 320.1307 .

6-Fluoro-4-(1H-indol-3-yl)-2-phenylquinoline (4b): Purified by column chromatography using 1:4 ethyl acetate and hexane. After concentration in vacuo a pale brown solid with a melting point of $154-156^{\circ} \mathrm{C}$ was obtained; IR (KBr): 3320, 3048, 1588, 1545, 1494,1240, 830, $750 \mathrm{~cm}^{-1}$. ${ }^{1} \mathrm{H}-\mathrm{NMR}$ (DMSO- $\left.d_{6}\right) \delta 11.81$ (s, 1H), 8.31-8.28 (m, 2H), $8.21(\mathrm{dd}, J=17.4,5.7 \mathrm{~Hz}, 1 \mathrm{H}), 8.16(\mathrm{~s}, 1 \mathrm{H}), 7.94(\mathrm{~d}, J=2.4 \mathrm{~Hz}, 1 \mathrm{H}), 7.79$ $(\mathrm{dd}, J=10.5,2.6 \mathrm{~Hz}, 1 \mathrm{H}), 7.70(\mathrm{dt}, J=8.4,2.7 \mathrm{~Hz}, 1 \mathrm{H}), 7.60-7.48(\mathrm{~m}, 5 \mathrm{H}), 7.24(\mathrm{t}, J=7.6 \mathrm{~Hz}, 1 \mathrm{H}), 7.13$ $(\mathrm{t}, J=7.8 \mathrm{~Hz}, 1 \mathrm{H}) ;{ }^{13} \mathrm{C}-\mathrm{NMR}\left(\mathrm{DMSO}-\mathrm{d}_{6}\right) \delta 159.3\left(\mathrm{~d}, J_{C-F}=244 \mathrm{~Hz}\right), 155.5\left(\mathrm{~d}, J_{C-F}=3 \mathrm{~Hz}\right), 145.7,142.5$ $\left(\mathrm{d}, J_{C-F}=3 \mathrm{~Hz}\right), 138.7,136.6,132.5\left(\mathrm{~d}, J_{C-F}=5 \mathrm{~Hz}\right), 129.5,128.8,127.2,126.7,126.4\left(\mathrm{~d}, J_{C-F}=9 \mathrm{~Hz}\right)$, 126.0, 122.0, 120.1, $119.6\left(\mathrm{~d}, J_{C-F}=25 \mathrm{~Hz}\right), 119.1,118.9,112.3,111.5,109.3\left(\mathrm{~d}, J_{C-F}=23 \mathrm{~Hz}\right)$; MS (EI) $m / z$ (relative intensity) $338\left(\mathrm{M}^{+}, 100\right), 337$ (65), 285 (24), 149 (87), 105 (30); HRMS (EI) $\mathrm{m} / z$ calcd for $\mathrm{C}_{23} \mathrm{H}_{15} \mathrm{~N}_{2} \mathrm{~F}\left(\mathrm{M}^{+}\right) 338.1219$, found 338.1213.

6-Chloro-4-(1H-indol-3-yl)-2-phenylquinoline (4c): Purified by column chromatography using 1:4 ethyl acetate and hexane. After concentration in vacuo a pale yellow solid with a melting point of 209-211 ${ }^{\circ} \mathrm{C}$ was obtained; ${ }^{1} \mathrm{H}-\mathrm{NMR}\left(\mathrm{DMSO}-d_{6}\right) \delta 11.83(\mathrm{~s}, 1 \mathrm{H}), 8.29(\mathrm{~d}, J=8.6 \mathrm{~Hz}, 2 \mathrm{H}), 8.16-8.13$ 
$(\mathrm{m}, 2 \mathrm{H}), 8.10(\mathrm{~d}, J=1.8 \mathrm{~Hz}, 1 \mathrm{H}), 7.94(\mathrm{~s}, 1 \mathrm{H}), 7.77(\mathrm{dd}, J=8.9,2.1 \mathrm{~Hz}, 1 \mathrm{H}), 7.60-7.48(\mathrm{~m}, 5 \mathrm{H}), 7.24(\mathrm{t}$, $J=7.3 \mathrm{~Hz}, 1 \mathrm{H}), 7.12(\mathrm{t}, J=7.7 \mathrm{~Hz}, 1 \mathrm{H}) ;{ }^{13} \mathrm{C}-\mathrm{NMR}\left(\mathrm{DMSO}-d_{6}\right) \delta 156.4,147.0,142.4,138.6,136.6,131.8$, $130.6,130.2,129.7,128.8,127.3,126.9,126.5,126.1,124.8,122.1,120.2,119.4,118.9,112.3,111.4$; MS (EI) $m / z$ (relative intensity) $356\left([\mathrm{M}+2]^{+}, 8\right), 354\left(\mathrm{M}^{+}, 24\right), 353$ (12), 149 (100); HRMS (EI) $m / z$ calcd for $\mathrm{C}_{23} \mathrm{H}_{15} \mathrm{~N}_{2} \mathrm{Cl}\left(\mathrm{M}^{+}\right)$354.0924, found 354.0919.

6-Bromo-4-(1H-indol-3-yl)-2-phenylquinoline (4d): Purified by column chromatography using 1:4 ethyl acetate and hexane. After concentration in vacuo a yellow solid with a melting point of $214-216{ }^{\circ} \mathrm{C}$ was obtained; ${ }^{1} \mathrm{H}-\mathrm{NMR}\left(\mathrm{DMSO}-d_{6}\right) \delta 11.83(\mathrm{~s}, 1 \mathrm{H}), 8.28(\mathrm{~d}, J=7.4 \mathrm{~Hz}, 2 \mathrm{H}), 8.26(\mathrm{~d}, J=1.8 \mathrm{~Hz}, 1 \mathrm{H})$, $8.15(\mathrm{~s}, 1 \mathrm{H}), 8.06(\mathrm{~d}, J=8.9 \mathrm{~Hz}, 1 \mathrm{H}), 7.93(\mathrm{~d}, J=2.1 \mathrm{~Hz}, 1 \mathrm{H}), 7.86(\mathrm{dd}, J=8.9,1.8 \mathrm{~Hz}, 1 \mathrm{H}), 7.60(\mathrm{~d}$, $J=8.1 \mathrm{~Hz}, 1 \mathrm{H}), 7.54-7.46(\mathrm{~m}, 4 \mathrm{H}), 7.24(\mathrm{t}, J=7.3 \mathrm{~Hz}, 1 \mathrm{H}), 7.11(\mathrm{t}, J=7.6 \mathrm{~Hz}, 1 \mathrm{H}) ;{ }^{13} \mathrm{C}-\mathrm{NMR}$ (DMSO- $\left.d_{6}\right)$ $\delta 156.5,147.2,142.3,138.6,136.6,132.7,131.9,129.7,128.8,128.1,127.4,127.0,126.9,126.1,122.1,120.2$, $119.4,119.2,118.9,112.3,111.4$; MS (EI) $m / z$ (relative intensity) $400\left([\mathrm{M}+2]^{+}, 100\right), 398\left(\mathrm{M}^{+}, 98\right), 319$ (34), 318 (27); HRMS (EI) $m / z$ calcd for $\mathrm{C}_{23} \mathrm{H}_{15} \mathrm{~N}_{2} \mathrm{Br}\left(\mathrm{M}^{+}\right)$398.0419, found 398.0417.

2-(2-Chlorophenyl)-4-(1H-indol-3-yl)quinoline (4e): Purified by column chromatography using 1:4 ethyl acetate and hexane. After concentration in vacuo a pale yellow solid with a melting point of 242-244 ${ }^{\circ} \mathrm{C}$ was obtained; ${ }^{1} \mathrm{H}-\mathrm{NMR}$ (DMSO- $\left.d_{6}\right) \delta 11.78(\mathrm{~s}, 1 \mathrm{H}), 8.26(\mathrm{~d}, J=8.2 \mathrm{~Hz}, 1 \mathrm{H}), 8.13(\mathrm{~d}$, $J=8.2 \mathrm{~Hz}, 1 \mathrm{H}), 7.88(\mathrm{~d}, J=2.6 \mathrm{~Hz}, 1 \mathrm{H}), 7.85-7.77(\mathrm{~m}, 3 \mathrm{H}), 7.65-7.51(\mathrm{~m}, 6 \mathrm{H}), 7.22(\mathrm{t}, J=7.3 \mathrm{~Hz}$, 1H), $7.12(\mathrm{t}, J=7.5 \mathrm{~Hz}, 1 \mathrm{H}) ;{ }^{13} \mathrm{C}-\mathrm{NMR}\left(\mathrm{DMSO}-d_{6}\right) \delta 156.3,148.4,141.7,139.3,136.6,131.8,131.3,130.2$, $129.8,129.6,129.6,127.4,126.8,126.6,126.1,126.0,125.4,122.0,122.0,120.1,118.8,112.2,111.4 ; \mathrm{MS}$ (EI) $m / z$ (relative intensity) $356\left([\mathrm{M}+2]^{+}, 42\right), 354\left(\mathrm{M}^{+}, 100\right)$; HRMS (EI) $m / z$ calcd for $\mathrm{C}_{23} \mathrm{H}_{15} \mathrm{~N}_{2} \mathrm{Cl}\left(\mathrm{M}^{+}\right)$ 354.0924, found 354.0924.

2-(2-Bromophenyl)-4-(1H-indol-3-yl)quinoline (4f): Purified by column chromatography using 1:4 ethyl acetate and hexane). After concentration in vacuo a pale yellow solid with a melting point of 236-238 ${ }^{\circ} \mathrm{C}$ was obtained; ${ }^{1} \mathrm{H}-\mathrm{NMR}\left(\mathrm{DMSO}_{6}\right) \delta 11.80(\mathrm{~s}, 1 \mathrm{H}), 8.27(\mathrm{~d}, J=7.9 \mathrm{~Hz}, 1 \mathrm{H}), 8.13(\mathrm{~d}$, $J=8.1 \mathrm{~Hz}, 1 \mathrm{H}), 7.88(\mathrm{~d}, J=2.6 \mathrm{~Hz}, 1 \mathrm{H}), 7.83-7.78(\mathrm{~m}, 3 \mathrm{H}), 7.73(\mathrm{dd}, J=7.6,1.6 \mathrm{~Hz}, 1 \mathrm{H}), 7.65-7.62$ $(\mathrm{m}, 2 \mathrm{H}), 7.58-7.52(\mathrm{~m}, 2 \mathrm{H}), 7.41(\mathrm{dt}, J=7.8,1.8 \mathrm{~Hz}, 1 \mathrm{H}), 7.22(\mathrm{t}, J=7.3 \mathrm{~Hz}, 1 \mathrm{H}), 7.11(\mathrm{t}, J=7.3 \mathrm{~Hz}, 1 \mathrm{H})$; ${ }^{13}$ C-NMR (DMSO- $d_{6}$ ) $\delta 157.8,148.3,141.7,141.3,136.6,132.9,131.7,130.3,129.6,129.6,127.8,126.8$, 126.6, 126.1, 126.0, 125.4, 122.0, 122.0, 121.1, 120.1, 118.9, 112.2, 111.4; MS (EI) $m / z$ (relative intensity) $400\left([\mathrm{M}+2]^{+}, 100\right), 399\left([\mathrm{M}+1]^{+}, 95\right), 398\left(\mathrm{M}^{+}, 90\right), 338$ (13), 319 (34), 204 (22), 159 (12); HRMS (EI) $m / z$ calcd for $\mathrm{C}_{23} \mathrm{H}_{15} \mathrm{~N}_{2} \mathrm{Br}\left(\mathrm{M}^{+}\right)$398.0419, found 398.0412.

4-(1H-Indol-3-yl)-2-p-tolylquinoline (4g): Purified by column chromatography using 1:4 ethyl acetate and hexane. After concentration in vacuo an orange solid with s melting point of $277-279{ }^{\circ} \mathrm{C}$ was obtained; IR (KBr): 3300, 3040, 1585, 1439, 1364, 1240, 814, $734 \mathrm{~cm}^{-1} .{ }^{1} \mathrm{H}-\mathrm{NMR}$ (DMSO- $\left.d_{6}\right) \delta 11.74$ $(\mathrm{s}, 1 \mathrm{H}), 8.21(\mathrm{~d}, J=8.1 \mathrm{~Hz}, 2 \mathrm{H}), 8.13(\mathrm{~d}, J=8.7 \mathrm{~Hz}, 2 \mathrm{H}), 8.09(\mathrm{~s}, 1 \mathrm{H}), 7.88(\mathrm{~d}, J=2.2 \mathrm{~Hz}, 1 \mathrm{H}), 7.78(\mathrm{t}$, $J=6.8 \mathrm{~Hz}, 1 \mathrm{H}), 7.57-7.51(\mathrm{~m}, 3 \mathrm{H}), 7.37(\mathrm{~d}, J=8.0 \mathrm{~Hz}, 2 \mathrm{H}), 7.23(\mathrm{t}, J=7.4 \mathrm{~Hz}, 1 \mathrm{H}), 7.11(\mathrm{t}, J=7.4 \mathrm{~Hz}$, 1H), $2.40(\mathrm{~s}, 3 \mathrm{H}) ;{ }^{13} \mathrm{C}-\mathrm{NMR}$ (DMSO- $\left.d_{6}\right) \delta 155.8,148.5,142.8,139.0,136.5,136.2,129.6,129.6,129.4$, 127.1, 126.5, 126.2, 126.0, 125.9, 125.6, 121.9, 120.0, 119.1, 118.3, 112.2, 112.0, 20.9; MS (EI) $\mathrm{m} / \mathrm{z}$ (relative intensity) $334\left(\mathrm{M}^{+}, 100\right)$; HRMS (EI) $m / z$ calcd for $\mathrm{C}_{24} \mathrm{H}_{18} \mathrm{~N}_{2}\left(\mathrm{M}^{+}\right) 334.1470$, found 334.1469.

4-(1H-Indol-3-yl)-2-(4-methoxyphenyl)quinoline (4h): Purified by column chromatography using 1:4 ethyl acetate and hexane. After concentration in vacuo a pale yellow solid with a melting point of 231-233 ${ }^{\circ} \mathrm{C}$ was obtained; ${ }^{1} \mathrm{H}-\mathrm{NMR}$ (DMSO- $\left.d_{6}\right) \delta 11.74(\mathrm{~s}, 1 \mathrm{H}), 8.28(\mathrm{td}, J=8.8,2.8 \mathrm{~Hz}, 2 \mathrm{H}), 8.11$ (ddd, $J=8.6,2.3,1.0 \mathrm{~Hz}, 2 \mathrm{H}), 8.08(\mathrm{~s}, 1 \mathrm{H}), 7.88(\mathrm{~d}, J=2.6 \mathrm{~Hz}, 1 \mathrm{H}), 7.77(\mathrm{ddd}, J=8.1,7.0,1.1 \mathrm{~Hz}, 1 \mathrm{H}), 7.57(\mathrm{~d}$, $J=8.1 \mathrm{~Hz}, 1 \mathrm{H}), 7.53-7.50(\mathrm{~m}, 2 \mathrm{H}), 7.23(\mathrm{ddd}, J=7.8,7.2,0.6 \mathrm{~Hz}, 1 \mathrm{H}), 7.13-7.09(\mathrm{~m}, 3 \mathrm{H}), 3.85(\mathrm{~s}, 3 \mathrm{H})$; ${ }^{13}$ C-NMR (DMSO- $d_{6}$ ) $\delta 160.5,155.5,148.5,142.6,136.5,131.4,129.5,129.5,128.6,126.4,126.3,125.9$, 125.6, 125.4, 121.8, 119.9, 119.1, 118.1, 114.1, 112.1, 112.1, 55.2; MS (EI) $m / z$ (relative intensity) $350\left(\mathrm{M}^{+}\right.$, 100), 349 (64); HRMS (EI) $m / z$ calcd for $\mathrm{C}_{24} \mathrm{H}_{18} \mathrm{~N}_{2} \mathrm{O}\left(\mathrm{M}^{+}\right) 350.1419$, found 350.1412.

2-(Benzo[d][1,3]dioxol-5-yl)-4-(1H-indol-3-yl)quinoline (4i): Purified by column chromatography using 1:3 ethyl acetate and hexane. After concentration in vacuo a yellow solid with a melting point of 
237-239 ${ }^{\circ} \mathrm{C}$ was obtained; ${ }^{1} \mathrm{H}-\mathrm{NMR}$ (DMSO- $\left.d_{6}\right) \delta 11.74(\mathrm{~s}, 1 \mathrm{H}), 8.10(\mathrm{~d}, J=8.4 \mathrm{~Hz}, 2 \mathrm{H}), 8.06(\mathrm{~s}, 1 \mathrm{H})$, 7.89-7.85 (m, 3H), $7.77(\mathrm{t}, J=7.2 \mathrm{~Hz}, 1 \mathrm{H}), 7.57-7.50(\mathrm{~m}, 3 \mathrm{H}), 7.22(\mathrm{t}, J=7.4 \mathrm{~Hz}, 1 \mathrm{H}), 7.13-7.07(\mathrm{~m}$, 2H), $6.12(\mathrm{~s}, 2 \mathrm{H}) ;{ }^{13} \mathrm{C}-\mathrm{NMR}$ (DMSO- $d_{6}$ ) $\delta 155.3,148.6,148.4,148.1,142.8,136.6,133.4,129.6,129.6$, 126.6, 126.3, 126.0, 125.8, 125.6, 121.9, 121.7, 120.0, 119.2, 118.3, 112.2, 112.1, 108.5, 107.3, 101.4; MS (EI) $m / z$ (relative intensity) $364\left(\mathrm{M}^{+}, 100\right)$; HRMS (EI) $m / z$ calcd for $\mathrm{C}_{26} \mathrm{H}_{14} \mathrm{~N}_{2} \mathrm{O}_{2}\left(\mathrm{M}^{+}\right) 364.1212$, found 364.1218 .

4-(1H-Indol-3-yl)-2-(naphthalen-2-yl)quinoline (4j): Purified by column chromatography using 1:4 ethyl acetate and hexane. After concentration in vacuo an orange solid with a melting point $>300{ }^{\circ} \mathrm{C}$ was obtained; ${ }^{1} \mathrm{H}-\mathrm{NMR}\left(\mathrm{DMSO}_{6}\right) \delta 11.77(\mathrm{~s}, 1 \mathrm{H}), 8.87(\mathrm{~s}, 1 \mathrm{H}), 8.54(\mathrm{~d}, J=8.5 \mathrm{~Hz}, 1 \mathrm{H}), 8.32(\mathrm{~s}, 1 \mathrm{H})$, $8.21(\mathrm{~d}, J=8.4 \mathrm{~Hz}, 1 \mathrm{H}), 8.16(\mathrm{~d}, J=8.3 \mathrm{~Hz}, 1 \mathrm{H}), 8.13-8.09(\mathrm{~m}, 2 \mathrm{H}), 8.01-7.99(\mathrm{~m}, 1 \mathrm{H}), 7.93(\mathrm{~s}, 1 \mathrm{H})$, $7.83(\mathrm{t}, J=7.2 \mathrm{~Hz}, 1 \mathrm{H}), 7.59-7.55(\mathrm{~m}, 5 \mathrm{H}), 7.24(\mathrm{t}, J=7.4 \mathrm{~Hz}, 1 \mathrm{H}), 7.13(\mathrm{t}, J=7.4 \mathrm{~Hz}, 1 \mathrm{H}) ;{ }^{13} \mathrm{C}-\mathrm{NMR}$ (DMSO- $d_{6}$ ) $\delta 155.7,148.5,143.0,136.6,136.3,133.4,133.1,129.7,129.7,128.8,128.3,127.5,126.9,126.8$, 126.6, 126.5, 126.3, 126.2, 126.1, 125.8, 124.8, 121.9, 120.0, 119.1, 118.8, 112.2, 112.0; HRMS (ESI) $\mathrm{m} / \mathrm{z}$ calcd for $\mathrm{C}_{27} \mathrm{H}_{19} \mathrm{~N}_{2}\left([\mathrm{M}+\mathrm{H}]^{+}\right)$371.1548, found 371.1554.

4-(1H-Indol-3-yl)-2-(thiophen-2-yl)quinoline (4k): Purified by column chromatography using 1:4 ethyl acetate and hexane. After concentration in vacuo a yellow solid with a melting point of $201-203{ }^{\circ} \mathrm{C}$ was obtained; IR (KBr): 3300, 3054, 1587, 1545, 1425, 1370, 1240, 811, $744 \mathrm{~cm}^{-1}$. ${ }^{1} \mathrm{H}-\mathrm{NMR}$ (DMSO- $d_{6}$ ) $\delta 11.75(\mathrm{~s}, 1 \mathrm{H}), 8.11(\mathrm{~s}, 1 \mathrm{H}), 8.08(\mathrm{~d}, J=8.4 \mathrm{~Hz}, 1 \mathrm{H}), 8.04(\mathrm{~d}, J=8.3 \mathrm{~Hz}, 1 \mathrm{H}), 8.01(\mathrm{~d}, J=3.7 \mathrm{~Hz}, 1 \mathrm{H}), 7.87$ $(\mathrm{d}, J=2.5 \mathrm{~Hz}, 1 \mathrm{H}), 7.78-7.73(\mathrm{~m}, 2 \mathrm{H}), 7.57(\mathrm{~d}, J=8.2 \mathrm{~Hz}, 1 \mathrm{H}), 7.53-7.50(\mathrm{~m}, 2 \mathrm{H}), 7.25-7.20(\mathrm{~m}, 2 \mathrm{H}), 7.11$ $(\mathrm{t}, J=7.8 \mathrm{~Hz}, 1 \mathrm{H}) ;{ }^{13} \mathrm{C}-\mathrm{NMR}\left(\mathrm{DMSO}-d_{6}\right) \delta 151.6,148.2,145.0,142.8,136.5,129.8,129.3,129.0,128.5$, 126.8, 126.6, 126.3, 126.1, 125.8, 125.8, 121.9, 120.0, 119.1, 117.4, 112.2, 111.7; MS (EI) $\mathrm{m} / \mathrm{z}$ (relative intensity) $326\left(\mathrm{M}^{+}, 100\right), 163(10), 84(13), 66$ (15); HRMS (EI) $m / z$ calcd for $\mathrm{C}_{21} \mathrm{H}_{14} \mathrm{~N}_{2} \mathrm{~S}\left(\mathrm{M}^{+}\right)$326.0878, found 326.0883 .

4-(5-Fluoro-1H-indol-3-yl)-2-phenylquinoline (41): Pale yellow crystalline solid (crystallized from ethyl acetate and hexane) with a melting point of $236-238{ }^{\circ} \mathrm{C} ;{ }^{1} \mathrm{H}-\mathrm{NMR}\left(\mathrm{DMSO}-d_{6}\right) \delta 11.87(\mathrm{~s}, 1 \mathrm{H}), 8.32(\mathrm{~d}$, $J=7.4 \mathrm{~Hz}, 2 \mathrm{H}), 8.16(\mathrm{~d}, J=8.4 \mathrm{~Hz}, 1 \mathrm{H}), 8.11-8.10(\mathrm{~m}, 2 \mathrm{H}), 7.97(\mathrm{~d}, J=2.3 \mathrm{~Hz}, 1 \mathrm{H}), 7.80(\mathrm{t}, J=7.6 \mathrm{~Hz}$, $1 \mathrm{H}), 7.84-7.59(\mathrm{~m}, 5 \mathrm{H}), 7.22(\mathrm{dd}, J=9.9,1.8 \mathrm{~Hz}, 1 \mathrm{H}), 7.08(\mathrm{dt}, J=9.1,2.1 \mathrm{~Hz}, 1 \mathrm{H}) ;{ }^{13} \mathrm{C}-\mathrm{NMR}\left(\mathrm{DMSO}-d_{6}\right)$ $\delta 157.6\left(\mathrm{~d}, J_{C--F}=232 \mathrm{~Hz}\right), 155.9,128.5,142.4,139.0,133.3,129.8,129.7,129.4,128.8,128.6,127.3$, $126.6\left(\mathrm{~d}, J_{\mathrm{C}-F}=10 \mathrm{~Hz}\right), 126.2,125.9,125.6,118.6,113.3\left(\mathrm{~d}, J_{\mathrm{C}-F}=10 \mathrm{~Hz}\right), 112.3\left(\mathrm{~d}, J_{\mathrm{C}-F}=4 \mathrm{~Hz}\right), 110.3(\mathrm{~d}$, $\left.J_{C-F}=26 \mathrm{~Hz}\right), 103.9\left(\mathrm{~d}, J_{\mathrm{C}-F}=23 \mathrm{~Hz}\right.$ ); MS (EI) $\mathrm{m} / z$ (relative intensity) $338\left(\mathrm{M}^{+}, 100\right)$; HRMS (EI) $\mathrm{m} / \mathrm{z}$ calcd for $\mathrm{C}_{23} \mathrm{H}_{15} \mathrm{~N}_{2} \mathrm{~F}\left(\mathrm{M}^{+}\right) 338.1219$, found 338.1210.

4-(5-Chloro-1H-indol-3-yl)-2-phenylquinoline (4m): Yellow crystalline solid (crystallized from ethyl acetate and hexane) with a melting point of $204-206{ }^{\circ} \mathrm{C} ;{ }^{1} \mathrm{H}-\mathrm{NMR}$ (DMSO- $\left.d_{6}\right) \delta 11.97(\mathrm{~s}, 1 \mathrm{H}), 8.32$ $(\mathrm{d}, J=7.4 \mathrm{~Hz}, 2 \mathrm{H}), 8.16(\mathrm{~d}, J=8.4 \mathrm{~Hz}, 1 \mathrm{H}), 8.12(\mathrm{~s}, 1 \mathrm{H}), 8.07(\mathrm{~d}, J=8.3 \mathrm{~Hz}, 1 \mathrm{H}), 7.98(\mathrm{~s}, 1 \mathrm{H}), 7.80(\mathrm{t}$, $J=7.7 \mathrm{~Hz}, 1 \mathrm{H}), 7.60-7.48(\mathrm{~m}, 5 \mathrm{H}), 7.46(\mathrm{~d} J=1.0 \mathrm{~Hz}, 1 \mathrm{H}), 7.20(\mathrm{dd}, J=8.6,1.4 \mathrm{~Hz}, 1 \mathrm{H}) ;{ }^{13} \mathrm{C}-\mathrm{NMR}$ (DMSO-d $d_{6}$ ) $\delta 155.9,148.5,142.2,139.0,135.1,129.8,129.7,129.4,128.7,128.2,127.5,127.3,126.2,125.8$, 125.7, 124.7, 122.0, 118.8, 118.3, 113.8, 111.9; MS (EI) $m / z$ (relative intensity) 356 ([M + 2] $\left.]^{+}, 33\right), 354$ $\left(\mathrm{M}^{+}, 100\right)$; HRMS (EI) $m / z$ calcd for $\mathrm{C}_{23} \mathrm{H}_{15} \mathrm{~N}_{2} \mathrm{Cl}\left(\mathrm{M}^{+}\right)$354.0924, found 354.0924.

4-(5-Bromo-1H-indol-3-yl)-2-phenylquinoline (4n): Purified by column chromatography using 1:4 ethyl acetate and hexane). After concentration in vacuo a pale green solid with a melting point of $255-257^{\circ} \mathrm{C}$ was obtained; ${ }^{1} \mathrm{H}-\mathrm{NMR}$ (DMSO- $\left.d_{6}\right) \delta 12.00(\mathrm{~s}, 1 \mathrm{H}), 8.32(\mathrm{~d}, J=7.3 \mathrm{~Hz}, 2 \mathrm{H}), 8.16(\mathrm{~d}, J=8.4 \mathrm{~Hz}, 1 \mathrm{H})$, $8.12(\mathrm{~s}, 1 \mathrm{H}), 8.07(\mathrm{~d}, J=8.2 \mathrm{~Hz}, 1 \mathrm{H}), 7.97(\mathrm{~s}, 1 \mathrm{H}), 7.78(\mathrm{t}, J=7.5 \mathrm{~Hz}, 1 \mathrm{H}), 7.61-7.46(\mathrm{~m}, 6 \mathrm{H}), 7.34(\mathrm{~d}$, $J=8.6 \mathrm{~Hz}, 1 \mathrm{H}) ;{ }^{13} \mathrm{C}-\mathrm{NMR}\left(\mathrm{DMSO}-d_{6}\right) \delta 155.9,148.4,142.1,138.9,135.3,129.8,129.7,129.4,128.8,128.1$, 128.0, 127.3, 126.2, 125.8, 125.7, 124.5, 121.2, 118.8, 114.2, 112.5, 111.7; MS (EI) $m / z$ (relative intensity) $400\left([\mathrm{M}+2]^{+}, 85\right), 398\left(\mathrm{M}^{+}, 100\right)$; HRMS (EI) $m / z$ calcd for $\mathrm{C}_{23} \mathrm{H}_{15} \mathrm{~N}_{2} \mathrm{Br}\left(\mathrm{M}^{+}\right)$398.0419, found 398.0425.

4-(5-Methoxy-1H-indol-3-yl)-2-phenylquinoline (4o): White crystalline solid (crystallized from ethyl acetate and hexane) with a melting point of $183-185{ }^{\circ} \mathrm{C} ;{ }^{1} \mathrm{H}-\mathrm{NMR}$ (DMSO- $\left.d_{6}\right) \delta 11.63(\mathrm{~s}, 1 \mathrm{H}), 8.31$ $(\mathrm{dd}, J=7.2 \mathrm{~Hz}, 2 \mathrm{H}), 8.15(\mathrm{~d}, J=8.7 \mathrm{~Hz}, 2 \mathrm{H}), 8.13(\mathrm{~s}, 1 \mathrm{H}), 7.85(\mathrm{~d}, J=2.6 \mathrm{~Hz}, 1 \mathrm{H}), 7.79(\mathrm{dt}, J=7.0$, 
$1.8 \mathrm{~Hz}, 1 \mathrm{H}), 7.59-7.54(\mathrm{~m}, 3 \mathrm{H}), 7.52-7.46(\mathrm{~m}, 2 \mathrm{H}), 6.96(\mathrm{~d}, J=2.3 \mathrm{~Hz}, 1 \mathrm{H}), 6.88(\mathrm{dd}, J=8.8,2.4 \mathrm{~Hz}$, $1 \mathrm{H}), 3.67$ (s, 3H); ${ }^{13} \mathrm{C}-\mathrm{NMR}$ (DMSO- $\left.d_{6}\right) \delta 155.9,154.1,148.6,143.1,139.0,131.7,129.8,129.7,129.4$, 128.8, 127.3, 127.2, 126.6, 126.2, 126.0 125.7, 118.4, 113.0,112.1, 112.0, 100.9, 55.3; MS (EI) $\mathrm{m} / \mathrm{z}$ (relative intensity) $350\left(\mathrm{M}^{+}, 100\right), 349$ (18); HRMS (EI) $\mathrm{m} / z$ calcd for $\mathrm{C}_{24} \mathrm{H}_{18} \mathrm{~N}_{2} \mathrm{O}\left(\mathrm{M}^{+}\right) 350.1419$, found 350.1422 .

4-(7-Methyl-1H-indol-3-yl)-2-phenylquinoline (4p): Purified by column chromatography using 1:4 ethyl acetate and hexane. After concentration in vacuo a pale yellow solid with a melting point of 163-165 ${ }^{\circ} \mathrm{C}$ was obtained; ${ }^{1} \mathrm{H}-\mathrm{NMR}\left(\mathrm{DMSO}-d_{6}\right) \delta 11.74(\mathrm{~s}, 1 \mathrm{H}), 8.30(\mathrm{~d}, J=7.3 \mathrm{~Hz}, 2 \mathrm{H}), 8.15(\mathrm{~d}$, $J=8.7 \mathrm{~Hz}, 2 \mathrm{H}), 8.12(\mathrm{~s}, 1 \mathrm{H}), 7.88(\mathrm{~d}, J=2.6 \mathrm{~Hz}, 1 \mathrm{H}), 7.79(\mathrm{t}, J=7.7 \mathrm{~Hz}, 1 \mathrm{H}), 7.58-7.48(\mathrm{~m}, 4 \mathrm{H}), 7.37-7.34$ $(\mathrm{m}, 1 \mathrm{H}), 7.03-7.00(\mathrm{~m}, 2 \mathrm{H}), 2.58(\mathrm{~s}, 3 \mathrm{H}) ;{ }^{13} \mathrm{C}-\mathrm{NMR}\left(\mathrm{DMSO}-d_{6}\right) \delta 155.8,148.5,143.1,139.0,136.1,129.7$, $129.6,129.4,128.8,127.3,126.3,126.1,126.0,126.0,125.7,122.4,121.4,120.2,118.6,116.7,112.5,16.8$; MS (EI) $m / z$ (relative intensity) $334\left(\mathrm{M}^{+}, 100\right), 333(68)$; HRMS (EI) $m / z$ calcd for $\mathrm{C}_{24} \mathrm{H}_{18} \mathrm{~N}_{2}\left(\mathrm{M}^{+}\right) 334.1470$ found 334.1477 .

4-(1-Methyl-1H-indol-3-yl)-2-phenylquinoline (4q): White crystalline solid (from ethyl acetate and hexane) with a melting point of $138-140{ }^{\circ} \mathrm{C} ;{ }^{1} \mathrm{H}-\mathrm{NMR}\left(\mathrm{DMSO}-d_{6}\right) \delta 8.30(\mathrm{~d}, J=8.0 \mathrm{~Hz}, 2 \mathrm{H}), 8.17$ $(\mathrm{dd}, J=10.9,8.8 \mathrm{~Hz}, 2 \mathrm{H}), 8.11(\mathrm{~s}, 1 \mathrm{H}), 7.91(\mathrm{~s}, 1 \mathrm{H}), 7.80(\mathrm{dd}, J=8.0,7.1 \mathrm{~Hz}, 1 \mathrm{H}), 7.61(\mathrm{~d}, J=8.3 \mathrm{~Hz}, 1 \mathrm{H})$, 7.59-7.49 (m, 5H), $7.30(\mathrm{t}, J=7.4 \mathrm{~Hz}, 1 \mathrm{H}), 7.16(\mathrm{t}, J=7.6 \mathrm{~Hz}, 1 \mathrm{H}), 3.96(\mathrm{~s}, 3 \mathrm{H}) ;{ }^{13} \mathrm{C}-\mathrm{NMR}\left(\mathrm{DMSO}-d_{6}\right) \delta$ 155.8, 148.5, 142.4, 139.0, 137.0, 130.7, 129.7, 129.7, 129.4, 128.8, 127.2, 126.5, 126.1, 125.9, 125.6, 122.0, 120.3, 119.3, 118.4, 111.0, 110.5, 32.8; MS (EI) $\mathrm{m} / z$ (relative intensity) $334\left(\mathrm{M}^{+}, 100\right), 333$ (61); HRMS (EI) $m / z$ calcd for $\mathrm{C}_{24} \mathrm{H}_{18} \mathrm{~N}_{2}\left(\mathrm{M}^{+}\right) 334.1470$, found 334.1469.

4-(2-Methyl-1H-indol-3-yl)-2-phenylquinoline (4r): Purified by column chromatography using 1:4 ethyl acetate and hexane. After concentration in vacuo a brown solid with a melting point of $98-100{ }^{\circ} \mathrm{C}$ was obtained; ${ }^{1} \mathrm{H}-\mathrm{NMR}\left(\mathrm{DMSO}_{-} d_{6}\right) \delta 8.73(\mathrm{~s}, 1 \mathrm{H}), 8.29(\mathrm{~d}, J=8.4 \mathrm{~Hz}, 1 \mathrm{H}), 8.16(\mathrm{~d}, J=7.6 \mathrm{~Hz}, 2 \mathrm{H}), 7.87(\mathrm{~s}$, $1 \mathrm{H}), 7.81(\mathrm{~d}, J=8.3 \mathrm{~Hz}, 1 \mathrm{H}), 7.68(\mathrm{t}, J=7.9 \mathrm{~Hz}, 1 \mathrm{H}), 7.47(\mathrm{t}, J=7.3 \mathrm{~Hz}, 1 \mathrm{H}), 7.42-7.29(\mathrm{~m}, 4 \mathrm{H}), 7.17(\mathrm{t}$, $J=7.3 \mathrm{~Hz}, 1 \mathrm{H}), 7.07(\mathrm{t}, J=7.4 \mathrm{~Hz}, 1 \mathrm{H}), 2.21(\mathrm{~s}, 3 \mathrm{H}) ;{ }^{13} \mathrm{C}-\mathrm{NMR}\left(\mathrm{DMSO}-d_{6}\right) \delta 157.4,149.1,143.5,140.0$, 135.6, 133.8, 129.9, 129.8, 129.4, 129.0, 128.7, 127.9, 127.2, 126.8, 126.0, 121.9, 121.2, 120.3, 119.1, 110.9, $110.8,12.7$; MS (EI) $m / z$ (relative intensity) $334\left(\mathrm{M}^{+}, 100\right), 333$ (55), HRMS (EI) $m / z$ calcd for $\mathrm{C}_{24} \mathrm{H}_{18} \mathrm{~N}_{2}$ $\left(\mathrm{M}^{+}\right)$334.1470, found 334.1464.

2-Phenyl-4-(2-phenyl-1H-indol-3-yl)quinoline (4s): Purified by column chromatography using 1:4 ethyl acetate and hexane. After concentration in vacuo an orange solid with a melting point of $282-284{ }^{\circ} \mathrm{C}$ was obtained; ${ }^{1} \mathrm{H}-\mathrm{NMR}$ (DMSO- $\left.d_{6}\right) \delta 12.00(\mathrm{~s}, 1 \mathrm{H}), 8.21(\mathrm{~d}, J=7.3 \mathrm{~Hz}, 2 \mathrm{H}), 8.15(\mathrm{~d}, J=8.4 \mathrm{~Hz}, 1 \mathrm{H}), 8.04$ $(\mathrm{s}, 1 \mathrm{H}), 7.72-7.65(\mathrm{~m}, 2 \mathrm{H}), 7.60(\mathrm{~d}, J=8.1 \mathrm{~Hz}, 1 \mathrm{H}), 7.50-7.42(\mathrm{~m}, 5 \mathrm{H}), 7.22(\mathrm{t}, J=7.7 \mathrm{~Hz}, 1 \mathrm{H}), 7.26-7.16$ $(\mathrm{m}, 5 \mathrm{H}), 7.01(\mathrm{t}, J=7.5 \mathrm{~Hz}, 1 \mathrm{H}) ;{ }^{13} \mathrm{C}-\mathrm{NMR}\left(\mathrm{DMSO}_{-} d_{6}\right) \delta 155.9,148.4,143.6,138.7,136.3,135.9,131.9$, 129.7, 129.7, 129.5, 128.9, 128.8, 128.6, 127.7, 127.5, 127.2, 126.4, 126.1, 126.0, 122.4, 120.6, 120.1, 118.7, 111.7, 109.1; MS (EI) $m / z$ (relative intensity) $396\left(\mathrm{M}^{+}, 100\right), 395$ (36), 193 (14); HRMS (EI) $\mathrm{m} / z$ calcd for $\mathrm{C}_{29} \mathrm{H}_{20} \mathrm{~N}_{2}\left(\mathrm{M}^{+}\right) 396.1626$, found 396.1634 .

4-(1H-Indol-3-yl)-8-methyl-2-phenylquinoline (4t): Purified by column chromatography using 1:4 ethyl acetate and hexane. After concentration in vacuo a pale orange solid with a melting point of 102-104 ${ }^{\circ} \mathrm{C}$ was obtained; ${ }^{1} \mathrm{H}-\mathrm{NMR}\left(\mathrm{CDCl}_{3}\right) \delta 11.75(\mathrm{~s}, 1 \mathrm{H}), 8.35(\mathrm{~d}, J=7.5 \mathrm{~Hz}, 2 \mathrm{H}), 8.13(\mathrm{~s}, 1 \mathrm{H}), 7.99$ $(\mathrm{d}, J=8.3 \mathrm{~Hz}, 1 \mathrm{H}), 7.86(\mathrm{~d}, J=2.3 \mathrm{~Hz}, 1 \mathrm{H}), 7.63-7.46(\mathrm{~m}, 6 \mathrm{H}), 7.40(\mathrm{t}, J=8.1 \mathrm{~Hz}, 1 \mathrm{H}), 7.22(\mathrm{t}, J=7.2 \mathrm{~Hz}$, $1 \mathrm{H}), 7.10(\mathrm{t}, J=7.4 \mathrm{~Hz}, 1 \mathrm{H}), 2.87(\mathrm{~s}, 3 \mathrm{H}) ;{ }^{13} \mathrm{C}-\mathrm{NMR}\left(\mathrm{CDCl}_{3}\right) \delta 154.4,147.3,143.2,139.3,137.0,136.6$, 129.6, 129.3, 128.8, 127.2, 126.5, 126.4, 125.7, 124.0, 121.9, 120.0, 119.1, 118.3, 112.4, 112.2, 18.2; MS (EI) $m / z$ (relative intensity) $334\left(\mathrm{M}^{+}, 100\right), 333$ (30), 219 (30); HRMS (EI) $m / z$ calcd for $\mathrm{C}_{24} \mathrm{H}_{18} \mathrm{~N}_{2}\left(\mathrm{M}^{+}\right)$ 334.1470, found 334.1471.

4-(2,5-Dimethyl-1H-indol-3-yl)-2-phenylquinoline (4u): Purified by column chromatography using 1:4 ethyl acetate and hexane. After concentration in vacuo an orange solid with a melting point of 181-183 ${ }^{\circ} \mathrm{C}$ was obtained; ${ }^{1} \mathrm{H}-\mathrm{NMR}\left(\mathrm{CDCl}_{3}\right) \delta 8.27(\mathrm{~d}, J=8.4 \mathrm{~Hz}, 1 \mathrm{H}), 8.20(\mathrm{~d}, J=7.4 \mathrm{~Hz}, 3 \mathrm{H}), 7.90(\mathrm{~s}$, $1 \mathrm{H}), 7.84(\mathrm{~d}, J=8.3 \mathrm{~Hz}, 1 \mathrm{H}), 7.73(\mathrm{ddd}, J=8.1,7.1,1.0 \mathrm{~Hz}, 1 \mathrm{H}), 7.54(\mathrm{t}, J=7.2 \mathrm{~Hz}, 2 \mathrm{H}), 7.49-7.41(\mathrm{~m}$, $2 \mathrm{H}), 7.31(\mathrm{~d}, J=8.2 \mathrm{~Hz}, 1 \mathrm{H}), 7.12(\mathrm{~s}, 1 \mathrm{H}), 7.05(\mathrm{~d}, J=8.2 \mathrm{~Hz}, 1 \mathrm{H}), 2.38(\mathrm{~s}, 3 \mathrm{H}), 2.37(\mathrm{~s}, 3 \mathrm{H}) ;{ }^{13} \mathrm{C}-\mathrm{NMR}$ 
$\left(\mathrm{CDCl}_{3}\right) \delta 157.3,149.2,143.4,140.3,133.9,133.6,130.3,129.9,129.7,129.4,129.1,129.0,127.9,127.3$, 126.8, 126.1, 123.7, 121.2, 119.0, 110.9, 110.4, 21.7, 13.0; MS (EI) $m / z$ (relative intensity) $348\left(\mathrm{M}^{+}, 100\right)$, 347 (35), 166 (11); HRMS (EI) $m / z$ calcd for $\mathrm{C}_{25} \mathrm{H}_{20} \mathrm{~N}_{2}\left(\mathrm{M}^{+}\right)$348.1626, found 348.1632.

2-Phenylquinoline (5a): Purified by column chromatography using 1:6 ethyl acetate and hexane. After concentration in vacuo a white solid with a melting point of $84-86^{\circ} \mathrm{C}$ was obtained; ${ }^{1} \mathrm{H}-\mathrm{NMR}\left(\mathrm{CDCl}_{3}\right)$ $\delta 8.46(\mathrm{~d}, J=8.7 \mathrm{~Hz}, 1 \mathrm{H}), 8.28(\mathrm{~d}, J=7.1 \mathrm{~Hz}, 2 \mathrm{H}), 8.15(\mathrm{~d}, J=8.7 \mathrm{~Hz}, 1 \mathrm{H}), 8.08(\mathrm{~d}, J=7.8 \mathrm{~Hz}, 1 \mathrm{H}), 8.00(\mathrm{~d}$, $J=7.8 \mathrm{~Hz}, 1 \mathrm{H}), 7.79(\mathrm{ddd}, J=8.2,7.0,1.2 \mathrm{~Hz}, 1 \mathrm{H}), 7.62-7.45(\mathrm{~m}, 4 \mathrm{H}) ;{ }^{13} \mathrm{C}-\mathrm{NMR}\left(\mathrm{CDCl}_{3}\right) \delta 156.1,147.6$, 138.7, 137.2, 130.0, 129.6, 129.1, 128.9, 127.8, 127.2, 127.0, 126.5, 118.8; MS (EI) $m / z$ (relative intensity) $205\left(\mathrm{M}^{+}, 100\right), 204$ (78); HRMS (EI) $m / z$ calcd for $\mathrm{C}_{15} \mathrm{H}_{11} \mathrm{~N}\left(\mathrm{M}^{+}\right)$205.0891, found 205.0889.

8-Methyl-2-phenylquinoline (5v): Purified by column chromatography using 1:6 ethyl acetate and hexane. After concentration in vacuo an orange oil was obtained; ${ }^{1} \mathrm{H}-\mathrm{NMR}\left(\mathrm{CDCl}_{3}\right) \delta 8.30(\mathrm{~d}$, $J=7.5 \mathrm{~Hz}, 2 \mathrm{H}), 8.18(\mathrm{~d}, J=8.5 \mathrm{~Hz}, 1 \mathrm{H}), 7.91(\mathrm{~d}, J=8.5 \mathrm{~Hz}, 1 \mathrm{H}), 7.67(\mathrm{~d}, J=8.0 \mathrm{~Hz}, 1 \mathrm{H}), 7.61-7.54$ $(\mathrm{m}, 3 \mathrm{H}), 7.49(\mathrm{t}, J=7.1 \mathrm{~Hz}, 1 \mathrm{H}), 7.43(\mathrm{t}, J=7.5 \mathrm{~Hz}, 1 \mathrm{H}), 2.94(\mathrm{~s}, 3 \mathrm{H}) ;{ }^{13} \mathrm{C}-\mathrm{NMR}\left(\mathrm{CDCl}_{3}\right) \delta$ 155.7, 147.4, 140.1, 137.9, 137.1, 129.9, 129.4, 129.0, 127.7, 127.3, 126.2, 125.6, 118.4, 18.1; MS (EI) $\mathrm{m} / \mathrm{z}$ (relative intensity) $219\left(\mathrm{M}^{+}, 100\right)$; HRMS (EI) $m / z$ calcd for $\mathrm{C}_{16} \mathrm{H}_{13} \mathrm{~N}\left(\mathrm{M}^{+}\right)$219.1048, found 219.1044.

\section{Conclusions}

In summary, we have successfully developed a strategy for the synthesis of 4-indolylquinoline derivatives from 2-nitrochalcone derivatives in two steps. The process involves as a first step the Michael addition of indole to nitrochalcones under solvent free conditions catalyzed by sulfamic acid and the second step is a reductive cyclization of the 3-(1H-indol-3-yl)-3-(2-nitrophenyl)-1phenylpropan-1-one derivatives to 4-indolylquinoline derivatives via reductive cyclization by $\mathrm{Fe} / \mathrm{HCl}$ in ethanol. A wide substrate scope, clean reactions and high yields of the products are the main merits of this strategy. This procedure offers an easy, convenient and alternative method to existing methodologies for the synthesis of indolylquinoline derivatives.

Supplementary Materials: Supplementary materials can be accessed at: http:/ / www.mdpi.com/1420-3049/20/ 12/19862/s1.

Acknowledgments: Financial support for this work by the Ministry of Science and Technology of China (MOST 103-2113-M-003-008-MY3), National Taiwan Normal University (103-07-C) and Instrumentation Centre at National Taiwan Normal University is gratefully acknowledged. The authors are grateful to Hsiu-Ni Huan and Chiu-Hui He for providing mass and NMR spectral data presented in this paper.

Author Contributions: Ching-Fa Yao, Wen-Chang Chen, Chan-Chieh Lin, conceived and designed the experiments; Wen-Chang Chen, Chan-Chieh Lin, Chun-Wei Kuo, and Chia-Yu Huang performed the experiments; Chia-Yu Huang, Chun-Wei Kuo analyzed the data; Veerababurao Kavala and Ching-Fa Yao wrote the paper.

Conflicts of Interest: The authors declare no conflicts of interest.

\section{References}

1. Van Order, R.B.; Lindwall, H.G. Indole. Chem. Rev. 1942, 30, 69-96.

2. Finlayson, R.; Pearce, A.N.; Page, M.J.; Kaiser, M.; Bourguet-Kondracki, M.L.; Harper, J.L.; Webb, V.L.; Copp, B.R. Didemnidines A and B, Indole Spermidine Alkaloids from the New Zealand Ascidian Didemnum sp. J. Nat. Prod. 2011, 74, 888-892. [CrossRef] [PubMed]

3. Koyama, K.; Hirasawa, Y.; Nugroho, A.E.; Hosoya, T.; Hoe, T.C.; Chan, K.L.; Morita, H. Alsmaphorazines A and B, Novel Indole Alkaloids from Alstonia pneumatophore. Org. Lett. 2010, 12, 4188-4191. [CrossRef] [PubMed]

4. Afzal, O.; Kumar, S.; Haider, M.R.; Ali, M.R.; Kumar, R.; Jaggi, M.; Bawa, S. A review on anticancer potential of bioactive heterocycle quinoline. Eur. J. Med. Chem. 2015, 97, 871-910. [CrossRef] [PubMed]

5. Chung, P.Y.; Bian, Z.X.; Pun, H.Y.; Chan, D.; Chan, A.S.C.; Chui, C.H.; Tang, J.C.O.; Lam, K.H. Recent advances in research of natural and synthetic bioactive quinolones. Future Med. Chem. 2014, 7, 947-967. 
6. Michael, J.P. Quinoline, quinazoline and acridone alkaloids. Nat. Prod. Rep. 2005, 22, 627-646. [CrossRef] [PubMed]

7. Liu, C.Y.; Wu, P.T.; Wang, J.P.; Fan, P.W.; Hsieh, C.H.; Su, C.L.; Chiu, C.C.; Yao, C.F.; Fang, K. An indolylquinoline derivative promotes apoptosis in human lung cancer cells by impairing mitochondrial functions. Apoptosis 2015, 20, 1471-1482. [CrossRef] [PubMed]

8. Bhowal, S.K.; Lala, S.; Hazra, A.; Paira, P.; Banerjee, S.; Mondal, N.B.; Chakraborty, S. Synthesis and assessment of fertility-regulating potential of 2-(2" -chloroacetamidobenzyl)-3-( $3^{\prime}$-indolyl) quinoline in adult rats as a male contraceptive agent. Contraception 2008, 77, 214-222. [CrossRef] [PubMed]

9. Kuethe, J.T.; Wong, A.; Qu, C.; Smitrovich, J.; Davies, I.W.; Hughes, D.L. Synthesis of 5-Substituted-1Hindol-2-yl-1H-quinolin-2-ones: A Novel Class of KDR Kinase Inhibitors. J. Org. Chem. 2005, 70, 2555-2567. [CrossRef] [PubMed]

10. Payack, J.F.; Vazquez, E.; Matty, L.; Kress, M.H.; McNamara, J. A Concise Synthesis of a Novel Antiangiogenic Tyrosine Kinase Inhibitor. J. Org. Chem. 2005, 70, 175-178. [CrossRef] [PubMed]

11. Maguire, M.P.; Sheets, K.R.; McVety, K.; Spada, A.P.; Zilbersteint, A. A New Series of PDGF Receptor Tyrosine Kinase Inhibitors: 3-Substituted Quinoline Derivatives. J. Med. Chem. 1994, 37, 2129-2137. [CrossRef]

12. Oliva, B.; Miller, K.; Caggiano, N.; O’Neill, A.J.; Cuny, G.D.; Hoemann, M.Z.; Hauske, J.R.; Chopra, I. Biological Properties of Novel Antistaphylococcal Quinoline-Indole Agents. Antimicrob. Agents Chemother. 2003, 47, 458-466. [CrossRef] [PubMed]

13. Hoemam, M.Z.; Kumaravel, G.; Xie, R.L.; Rossi, R.F.; Meyer, S.; Sidhu, A.; Cunny, G.D.; Hauske, J.R. Potent In vitro methicillin-resistant Staphylococcus aureus activity of 2-(1H-indol-3-yl)quinoline derivatives. Bioorg. Med. Chem. Lett. 2000, 10, 2675-2678. [CrossRef]

14. Birkinshaw, T.N.; Teague, S.J.; Beech, C.; Bonnert, R.V.; Hill, S.; Patel, A.; Reakes, S.; Sanganee, H.; Dougall, I.G.; Phillips, T.T.; et al. Discovery of potent CRTh2 $\left(\mathrm{DP}_{2}\right)$ receptor antagonists. Bioorg. Med. Chem. Lett. 2006, 16, 4287-4290. [CrossRef] [PubMed]

15. Kuriyama, M.; Matsuo, S.; Shinozawa, M.; Onomura, O. Ether-Imidazolium Carbenes for Suzuki-Miyaura Cross-Coupling of Heteroaryl Chlorides with Aryl/Heteroarylboron Reagents. Org. Lett. 2013, 15, 2716-2719. [CrossRef] [PubMed]

16. Kumar, K.S.; Kumar, S.K.; Sreenivas, B.Y.; Gorja, D.R.; Kapavarapu, R.; Rambabu, D.; Krishna, G.R.; Reddy, C.M.; Rao, M.V.B.; Parsa, K.V.L.; Pal, M. C-C bond formation at C-2 of a quinoline ring: Synthesis of 2-(1H-indol-3-yl)quinoline-3-carbonitrile derivatives as a new class of PDE4 inhibitors. Bioorg. Med. Chem. 2012, 20, 2199-2207. [CrossRef] [PubMed]

17. Brasse, M.; Ellman, J.A.; Bergman, R.G. A facile, metal- and solvent-free, autoxidative coupling of quinolones with indoles and pyrroles. Chem. Commun. 2011, 5019-5021. [CrossRef] [PubMed]

18. Mahato, S.B.; Mandal, N.B.; Chattopadhyay, S.; Nandia, G.; Luger, P.; Weber, M. Synthesis of indolylquinolines under Friedel-Crafts reaction conditions. Tetrahedron 1994, 50, 10803-10812. [CrossRef]

19. Khalafi-Nezhad, A.; Sarikhani, S.; Shahidzadeh, E.S.; Panahi, F. L-Proline-promoted three-component reaction of anilines, aldehydes and barbituric acids/malononitrile: Regioselective synthesis of 5-arylpyrimido[4,5-b]quinoline-diones and 2-amino-4-arylquinoline-3-carbonitriles in water. Green Chem. 2012, 14, 2876-2884. [CrossRef]

20. Kumar, S.; Sahu, D.P. Friedel-Crafts heteroarylation of (hetero)arenes: A facile entry to 4-(hetero)aryl quinazolines and quinolones. J. Hetero. Chem. 2009, 46, 748-755. [CrossRef]

21. Nishida, A.; Miyashita, N.; Fuwa, M.; Nakagawa, M. Synthesis of (3-indolyl)heteroaromatics by suzuki-miyaura coupling and their inhibitory activity in lipid peroxidation. Heterocycles 2003, 59, 473-476. [CrossRef]

22. Ciattini, P.G.; Morera, E.; Ortar, G. An efficient synthesis of 3-substituted indoles by palladium-catalyzed coupling reaction of 3-tributylstannylindoles with organic triflates and halides. Tetrahedron Lett. 1994, 35, 2405-2408. [CrossRef]

23. Arcadi, A.; Chiarini, M.; Marinelli, F.; Picchini, S. A Concise One-Pot Approach to the Synthesis of 4-(1H-Indol-3-yl)quinolones. Synthesis 2011, 4084-4090.

24. Zanwar, M.R.; Gawande, S.D.; Kavala, V.; Kuo, C.-W.; Yao, C.-F. Iron(III) Chloride Catalyzed Synthesis of Highly Substituted Indolyl-Tetrahydroquinoline Derivatives by Using Indolylnitroalkene as Dienophiles 
and Its Application to the Synthesis of Indolo-Benzonaphthyridine Derivatives. Adv. Synth. Catal. 2014, 356, 3849-3860. [CrossRef]

25. Rajawinslin, R.R.; Ichake, S.S.; Kavala, V.; Gawande, S.D.; Huang, Y.-H.; Kuo, C.-W.; Yao, C.-F. Iron/acetic acid mediated synthesis of 6,7 -dihydrodibenzo $[b, j][1,7]$ phenanthroline derivatives via intramolecular reductive cyclization. RSC Adv. 2015, 5, 52141-52153. [CrossRef]

26. Rajawinslin, R.R.; Gawande, S.D.; Kavala, V.; Huang, Y.-H.; Kuo, C.-W.; Kuo, T.-S.; Chen, M.-L.; He, C.-H.; Yao, C.-F. Iron/acetic acid mediated intermolecular tandem C-C and C-N bond formation: an easy access to acridinone and quinoline derivatives. RSC Adv. 2014, 4, 37806-37811. [CrossRef]

27. Ramesh, C.; Lei, P.M.; Janreddy, D.; Kavala, V.; Kuo, C.-W.; Yao, C.-F. Synthesis of Indolylquinolines, Indolylacridines, and Indolylcyclopenta[b]quinolines from the Baylis-Hillman Adducts: An in Situ [1,3]-Sigmatropic Rearrangement of an Indole Nucleus to Access Indolylacridines and Indolylcyclopenta[b]quinolones. J. Org. Chem. 2012, 77, 8451-8464. [CrossRef] [PubMed]

28. Janreddy, D.; Kavala, V.; Bosco, J.W.; Kuo, C.-W.; Yao, C.-F. An Easy Access to Carbazolones and 2,3-Disubstituted Indoles. Eur. J. Org. Chem. 2011, 2360-2365. [CrossRef]

29. Ramesh, C.; Raju, B.R.; Kavala, V.; Kuo, C.-W.; Yao, C.-F. A simple and facile route for the synthesis of $2 H$-1,4-benzoxazin-3-(4H)-ones via reductive cyclization of 2-(2-nitrophenoxy) acetonitrile adducts in the presence of Fe/acetic acid. Tetrahedron 2011, 67, 1187-1192. [CrossRef]

30. Ramesh, C.; Kavala, V.; Kuo, C.-W.; Raju, B.R.; Yao, C.-F. An Unprecedented Route for the Synthesis of 3, 3'-Biindoles by Reductive Cyclization of 3-[2-Nitro-1-(2-nitrophenyl)ethyl]-1H-indoles Mediated by Iron/Acetic Acid. Eur. J. Org. Chem. 2010, 3796-3801. [CrossRef]

31. Ramesh, C.; Kavala, V.; Raju, B.R.; Kuo, C.-W.; Yao, C.-F. A simple and facile route for the synthesis of $2 H$-1, 4-benzoxazin-3-(4H)-ones via reductive cyclization of 2-(2-nitrophenoxy) acetonitrile adducts in the presence of Fe/acetic acid. Tetrahedron Lett. 2010, 51, 5234-5237. [CrossRef]

32. Ramesh, C.; Kavala, V.; Raju, B.R.; Kuo, C.-W.; Yao, C.-F. Novel synthesis of indolylquinoline derivatives via the C-alkylation of Baylis-Hillman adducts. Tetrahedron Lett. 2009, 50, 4037-4041. [CrossRef]

33. Lee, K.Y.; Lee, Y.; Kim, J.N. Synthesis of $\beta, \gamma$-Disubstituted $\alpha$-Methylene- $\gamma$-butyrolactams Starting from the Baylis-Hillman Adducts. Bull. Korean Chem. Soc. 2007, 28, 143-146. [CrossRef]

34. Basavaiah, D.; Rao, J.S.; Raju, J. Simple, Facile, and One-Pot Conversion of the Baylis-Hillman Adducts into Functionalized 1,2,3,4-Tetrahydroacridines and Cyclopenta[b]quinolones. J. Org. Chem. 2004, 69, 7379-7382. [CrossRef] [PubMed]

35. Jonsson, S.; Arribas, C.S.; Wendt, O.F.; Siegel, J.S.; Warnmark, K. Synthesis of 2-pyridone-fused 2,2'-bipyridine derivatives. An unexpectedly complex solid state structure of 3,6-dimethyl-9H-4,5,9triazaphenanthren-10-one. Org. Biomol. Chem. 2005, 3, 996-1001. [CrossRef] [PubMed]

36. Basavaiah, D.; Raju, J.; Rao, J.S. Applications of Baylis-Hillman adducts: a simple, convenient, and one-pot synthesis of 3-benzoylquinolines. Tetrahedron Lett. 2006, 47, 73-77. [CrossRef]

37. Mahmoudi, A.; Jafari, A.S.; Saeedi, H. Firouzabadi Sulfonic acid-functionalized magnetic nanoparticles as a recyclable and eco-friendly catalyst for atom economical Michael addition reactions and bis indolyl methane synthesis. RSC Adv. 2015, 5, 3023-3030. [CrossRef]

38. Li, S.-S.; Lin, H.; Zhanga, X.-M.; Dong, L. Ruthenium-catalyzed direct C3 alkylation of indoles with $\alpha, \beta$-unsaturated ketones. Org. Biomol. Chem. 2015, 13, 1254-1263. [CrossRef] [PubMed]

39. Veisi, H.; Maleki, B.; Eshbala, H.; Veisi, H.; Masti, R.; Ashrafi, S.S.; Baghayeri, M. In situ generation of Iron(III) dodecyl sulfate as Lewis acid-surfactant catalyst for synthesis of bis-indolyl, tris-indolyl, Di(bis-indolyl), Tri(bis-indolyl), tetra(bis-indolyl)methanes and 3-alkylated indole compounds in water. RSC Adv. 2014, 4, 30683-30688. [CrossRef]

40. Gohain, M.; Jacobs, J.; Marais, C.; Bezuidenhoudt, B.C.B. Al(OTf) ${ }_{3}$ Catalysed Friedel-Crafts Michael Type Addition of Indoles to $\alpha, \beta$-Unsaturated Ketones with PEG-200 as Recyclable Solvent. Aust. J. Chem. 2013, 66, 1594-1599. [CrossRef]

41. Zhan, Z.-P.; Yang, R.-F.; Lang, K. Samarium triiodide-catalyzed conjugate addition of indoles with electron-deficient olefins. Tetrahedron Lett. 2005, 46, 3859-3862. [CrossRef]

42. Kumar, V.; Kaur, S.; Kumar, S. $\mathrm{ZrCl}_{4}$ catalyzed highly selective and efficient Michael addition of heterocyclic enamines with $\alpha, \beta$-unsaturated olefins. Tetrahedron Lett. 2006, 47, 7001-7005. [CrossRef] 
43. Yin, P.; Liu, N.; Deng, Y.-X.; Chen, Y.; Deng, Y.; He, L. Synthesis of 2,4-Diaminoquinazolines and Tricyclic Quinazolines by Cascade Reductive Cyclization of Methyl N-Cyano-2-nitrobenzimidates. J. Org. Chem. 2012, 77, 2649-2658. [CrossRef] [PubMed]

44. Sandelier, M.J.; Shong, P.D. Reductive Cyclization of O-Nitrophenyl Propargyl Alcohols: Facile Synthesis of Substituted Quinolines. Org. Lett. 2007, 9, 3209-3212. [CrossRef] [PubMed]

Sample Availability: Samples of the compounds $\mathbf{3 a - 3 v}, \mathbf{4 a - 4} \mathbf{u}$ are available from the authors.

(C) 2015 by the authors; licensee MDPI, Basel, Switzerland. This article is an open access article distributed under the terms and conditions of the Creative Commons by Attribution (CC-BY) license (http:/ / creativecommons.org/licenses/by/4.0/). 